NBER WORKING PAPER SERIES

\title{
TECHNOLOGY AND THE TASK CONTENT OF JOBS ACROSS THE DEVELOPMENT SPECTRUM
}

\author{
Julieta Caunedo \\ Elisa Keller \\ Yongseok Shin \\ Working Paper 28681 \\ http://www.nber.org/papers/w28681
NATIONAL BUREAU OF ECONOMIC RESEARCH 1050 Massachusetts Avenue
Cambridge, MA 02138
April 2021

This paper is an invited contribution to the Structural Transformation and Economic Growth (STEG) initiative of the Center for Economic and Policy Research (CEPR). Caunedo and Keller gratefully acknowledge CEPR's financial support. We greatly benefited from many helpful suggestions by Doug Gollin, Joe Kaboski, other members of STEG's Academic Steering Committee, and an anonymous reviewer. We thank Lucia Casal and Luming Chen for their outstanding research assistance. The views expressed herein are those of the authors and do not necessarily reflect the views of the National Bureau of Economic Research.

NBER working papers are circulated for discussion and comment purposes. They have not been peer-reviewed or been subject to the review by the NBER Board of Directors that accompanies official NBER publications.

(C) 2021 by Julieta Caunedo, Elisa Keller, and Yongseok Shin. All rights reserved. Short sections of text, not to exceed two paragraphs, may be quoted without explicit permission provided that full credit, including $\left({ }^{\circ}\right.$ notice, is given to the source. 
Technology and the Task Content of Jobs across the Development Spectrum

Julieta Caunedo, Elisa Keller, and Yongseok Shin

NBER Working Paper No. 28681

April 2021

JEL No. J16,J24,O33

\begin{abstract}
$\underline{\text { ABSTRACT }}$
Technology is the driver of labor allocation across sectors and occupations. Is the impact of technological change on developing countries similar to its impact on developed countries? Will developing countries follow the same development path that developed economies have taken? Our approach focuses on how technology shifts and reshapes the tasks workers perform on the job, and views occupations as the natural observable stand-in for these tasks. We first take stock of our knowledge on how technological change reallocates labor. We then construct a new measure of occupational task contents for each country and present new evidence on countries' task intensity. In the cross section, developed countries use non-routine analytical and interpersonal tasks more intensively than developing countries, but less intensively use routinecognitive and routine-manual tasks. Both the occupational employment share and the occupational task contents of a country matter for these relationships. In the time dimension, countries with high initial task intensities experienced a decline in these intensities, suggesting convergence in task intensities across countries. Our results show that occupational task contents ought to be measured for each country for proper analysis. More broadly, we should not simply extrapolate what we know about the impact of technology on the labor market in developed countries to developing countries.
\end{abstract}

Julieta Caunedo

452 Uris Hall

Cornell University

Ithaca, NY 14853

jdc364@cornell.edu

Elisa Keller

University of Exeter

0.45 Streatham Court

Rennes Drive

Exeter, EX4 4PU

United Kingdom

e.keller@exeter.ac.uk
Yongseok Shin

Department of Economics

Washington University in St. Louis

One Brookings Drive

St. Louis, MO 63130

and NBER

yshin@wustl.edu 


\section{Introduction}

Most developed countries underwent a similar arc of structural change, or the reallocation of economic activity from agriculture to manufacturing and then to services. Economists agree that the differential rates of technological progress across these sectors have shaped their uneven growth. Until recently, the large literature on structural change has viewed labor as a homogeneous quantity to be freely allocated across sectors. A more recent literature, utilizing richer microeconomic data, has explored how technological change differentially affects workers across the demographic and socioeconomic spectrum. One important insight of this literature is that a worker's occupation is the relevant unit of analysis for identifying the pattern of technological change. Most works in this occupation-based literature focus on the United States and other developed economies because of data availability.

An important question to be answered is whether developing countries will retrace the path of the developed countries - or, is there a "natural" pattern of worker allocation across occupations and sectors along the process of economic development? There is evidence that the pattern of structural change has shifted for many developing countries, i.e., "premature deindustrialization" (Rodrik, 2016). One possible explanation is that the availability and adoption of new technologies, automation in particular, may be eliminating low-skill manufacturing jobs that used to be gateways for workers leaving the agricultural sector (Hallward-Driemeier and Nayyar, 2017; Acemoglu and Restrepo, 2019). In other words, by redefining the nature of economic activity and the role of workers in a given occupation or sector, technological change can upend the once stable relationship between economic development and structural change. Answering the question, then, requires that we identify the pattern of technological change in developing countries.

Our approach focuses on how technology shifts and reshapes the tasks workers perform on the job, and views occupations as the natural observable stand-in for these tasks. This approach enables a richer analysis than what has been possible in the vast literature on skill-biased technology, the dominant macroeconomic view on the impact of technological change on the labor market, or in the structural change literature, whose unit of analysis is sectors. There are three reasons. First, it focuses on workers' role in the labor market directly, instead of grouping them into broad categories (skilled vs. unskilled) based on their educational attainment. Second, it naturally brings into analysis occupational choices, which are subject to labor market frictions and the loss of job-specific human capital. Third, it opens the door to better measuring technological change by observing how workers' tasks evolve over time, instead of inferring them as a residual from sector-level growth accounting. 
Our paper has two goals. The first is to take stock of our knowledge on the role of technological change in shaping the allocation of workers across occupations and sectors. The other is to motivate further research in this area using data from developing countries. For this purpose, we harmonize and analyze relevant data from countries across the economic development spectrum.

We start by reviewing the literature on worker reallocation across tasks. The literature has standardized methods designed for developed country data. We bring to attention the small literature that applies those methodologies to the data from developing countries. Next, we construct a new measure of the task content of occupations that varies across countries. We analyze how the task intensity of workers varies across occupations, demographic groups (by gender in particular), and countries. We also present new evidence on how the task intensity of countries has changed over time, together with the changes in worker allocation across occupations and sectors. Our analysis highlights the importance of measuring occupational task contents at the country level. It also shows that, when measuring structural change by labor reallocation, changes in the occupational composition of the labor force account for a larger part of that labor reallocation than do changes in the sector-level employment. Finally, we offer a theoretical framework to highlight channels inducing differences in the task content of an occupation across countries. We then use the implications of the theory to put forward open questions for future research on structural change along with the data challenges they entail. We conclude by summarizing the implications of current and future research for policy makers.

\section{Technological Change and Employment across Oc- cupations}

How does technological change affect workers? The recent rise in automation and displacement of workers have heightened our interest in the effect of technology on wages and employment. The exposure of labor to technological change can be measured by the response of labor demand to technological change (Hicks, 1932; Robinson, 1934). Katz and Murphy (1992) were the first to highlight the increase in the relative demand for educated workers as the cause of the rise in skill premium and skill acquisition over the last century in the US. In the more recent task-based models of production, as reviewed in Acemoglu and Autor (2011), technological progress affects the demand for labor by increasing the productivity of workers and other factors of production at the level of tasks or introducing new tasks altogether (Acemoglu and Restrepo, 2019). This reallocates workers across the task spectrum 
and ultimately changes the tasks a given type of worker performs.

One of the most salient labor market phenomena in developed countries over the last 40 years is job polarization, or workers moving out of middle-skill occupations into low-skill and high-skill occupations. This polarization is explained by technological change that enabled machines to replace middle-skill workers performing tasks that are routine in nature: i.e., the routinization hypothesis. Autor et al. (2006) and Autor and Dorn (2013) provided evidence for the US, and Goos et al. (2014) for other developed economies. Beaudry et al. (2016) showed that the decline of middle-skill jobs was first mirrored by the rise of high-skill jobs but after 2000 increasingly by the rise of low-skill jobs. Autor et al. (2003), Aum (2017) and Aum et al. (2018) point to the role of computerization and Caunedo et al. (2019) to the technological change embodied in a broader set of tools that workers use.

Recent works show that polarization and structural change from manufacturing to services are interconnected. Barany and Siegel (2018) point to the tight connection between the loss of routine jobs and the decline of manufacturing, and Lee and Shin (2017) show that polarization took place within services as well as within manufacturing, although the pace was faster in manufacturing. ${ }^{1}$

It seems productive then to take this approach to developing country data. The task contents of jobs and occupational employments in developing countries can help identify the direction of technological progress and account for past and future structural changes. Ultimately, this approach may lead to new implications for cross-country income differences.

A few papers have started to look at differences in the occupational composition of the labor force across countries. Vizcaino (2019) documents that developed countries have disproportionately more workers in high-skill intensive occupations. Gottlieb et al. (2020) report that workers in developing countries are employed in occupations that are less amenable to be executed from home than workers in developed countries. Less is known about the change in occupational employment for developing countries. Maloney and Molina (2016) show that the occupational employment changes in developing countries did not feature a hollowing out of middle-skill jobs. Das and Hilgenstock (2018) tested the routinization hypothesis for a large set of countries, with the assumption that the task content (routineness in particular) of a given occupation is the same in all countries. They find that in developing countries the employment in routine-intensive occupations was small in 1990 but has grown over the years, which is the exact opposite of what happened in developed economies. Lewandowski

\footnotetext{
${ }^{1}$ Duernecker and Herrendorf (2016) is another paper showing that occupation-level technological change can result in structural change, because some occupations are manufacturing occupations and others are service occupations.
} 
et al. (2020) allow the task content of a given occupation to differ across countries in a systematic matter, and construct an imputed measure of the routineness of jobs in developing countries. They find that developing countries also experienced a shift away from routine to non-routine jobs (or "de-routinization" of jobs), contradicting Das and Hilgenstock (2018), but its pace was slower than in developed countries. Lo Bello et al. (2019) also show that the assumption of equal task contents of an occupation across countries underestimates the job de-routinization in developing countries.

What can explain these different patterns between developed and developing countries? There are several possible answers, although they have not been examined rigorously. First, the higher price of capital relative to consumption (Hsieh and Klenow, 2007) and the scarcity of skilled labor in developing countries (Caselli and Coleman, 2006) may deter the adoption of technology that causes de-routinization. Second, as suggested by Lo Bello et al. (2019) and Das and Hilgenstock (2018), trade is a force offsetting de-routinization in developing countries: Routine jobs are being offshored from developed to (at least some) developing countries. These two suggest that developed and developing countries are effectively exposed to (or choose to adopt) a different set of technologies and paths of technological change. Third, labor markets may respond differently to the same technological change, depending on labor market frictions, training costs and demographics. There is indeed some evidence on a disparate effect of information and communications technology (ICT) across countries in different stages of development. Consistent with the effect of computerization in the US, Akerman et al. (2015) found in Norway that broad-band internet had favorable effects on skilled workers but not on unskilled workers performing routine tasks. However, Hjort and Poulsen (2019) found that the introduction of broad-band internet in a group of sub-Saharan African countries had large positive effects on the employment of less educated workers, as well as highly educated workers. This does not necessarily mean that the same technological change always affects developed and developing countries differently. Lo Bello et al. (2019) find that the adoption of ICT in developing countries correlates with a decline in routinecognitive jobs, consistent with the evidence from the computerization in the US and Western Europe. $^{2}$

We draw two lessons from the literature. First, technological change is central to the pattern of labor allocation across occupations and sectors. Second, technological change can redefine the task content of an occupation. In addition, while the literature on devel-

\footnotetext{
${ }^{2}$ However, not all ICT replaces routine jobs and complement abstract jobs. Software in particular can have the effect of reducing the demand for workers performing abstract tasks, as shown for the US by Aum (2017) and for Chile by Almeida et al. (2017). In addition, artificial intelligence (AI) is also expected to replace some abstract, cognitive-intensive jobs (Aghion et al., 2018, 2020).
} 
oped economies favours the mapping between detailed occupations and the one task they perform most intensively, when using more aggregated occupational classifications of developing countries, we find it useful to consider an occupation as a collection of tasks.

In the next two sections, we empirically address the question of technological change and its impact on labor allocation. A reasonable conjecture is that the task contents of occupations change systematically with the level of economic development. For example, a clerk at a bank in Mombasa, Kenya may perform tasks that are different from those performed by a clerk at a bank in the City of London. If developing countries operate older and more labor-intensive technologies, the link between technological change and tasks implies that this technology difference will show up as differences in task contents of occupations across countries. We first develop a country-specific measure of task intensity for occupations, based on surveys and employment data from countries covering a large swath of income levels. Relative to the literature, we are significantly expanding the set of countries in our analysis. We then document how task intensity varies across countries and over time. Our empirical findings naturally raise new research questions, some of which are outlined using a simple theoretical framework in Section 5.

\section{Occupational Task Contents across Countries}

In this section, we document the task contents of production across the development spectrum, in the aggregate and by demographic groups. We separate the roles of the tasks performed by workers within an occupation and of the distribution of workers across occupations in shaping these cross-country patterns.

For this purpose, we combine information on the task content of occupations by leveraging the Survey of Adult Skills within the OECD's Programme for the International Assessment of Adult Competencies (PIAAC) and the World Bank's STEP Skills Measurement Program (STEP). PIAAC is designed to elicit adults' proficiency in key information-processing skills at work, such as literacy, numeracy and problem solving. It provides information on the tasks performed by 1-digit occupations in 41 countries at different levels of development, of which 35 countries have full information on occupational categories that can be merged with 1-digit occupational employment data from the International Labour Organization (ILO). The poorest country in this sample is Ecuador and the richest is Singapore. The survey collects data on how intensively and how often broad categories of tasks are performed in the workplace by occupation. These categories are: cognitive skills, interaction and social skills, physical skills, and learning skills. 
STEP is designed to measure skills of the labor force in poor and middle-income countries. It covers 16 countries of which 9 have full information on occupational task contents and employment shares. The poorest country in this sample is Ghana and the richest is Macedonia. STEP only surveys those in urban areas.

Questionnaires are similar between PIAAC and STEP, but they have different integer scales for the answers. These disparities in scale could generate systematic differences in answers through extreme responding behavior - i.e., respondents tend to choose the extremes of the options, which makes the surveys not comparable, even after standardization.

To overcome this hurdle, we exploit questions on computer usage, because they are posed in exactly the same manner in both surveys with the same response scales. From the answers to computer usage questions, we predict the responses that we would have observed in STEP for all available tasks if STEP had the same response scale as PIAAC. The main assumption for the validity of this imputation is that the relationship between task contents and computer usage in the middle- and high-income countries from PIAAC applies to the poorer economies in STEP. We find that the relationship between task content and GDP per capita follows the same trend for the PIAAC sample and the full sample with STEP imputation, except for the non-routine analytical (NRA) tasks. ${ }^{3}$ In this section, we report the results using the STEP imputation. In the Data Appendix we report the same results using the raw STEP data.

\subsection{Task Intensity}

We start by documenting systematic cross-country differences in task intensity. For each task category $i$, a measure of task content is constructed for each occupation $o$ and country $c: \tau_{i o c}$. For any task $i$, We can rank occupations by this measure. ILO provides employment data by occupation at the 1-digit level, the highest degree of aggregation for ISCO-08. ${ }^{4}$ We then use the share of workers in occupation $o$ for country $c$ from ILOSTATS, $s_{o c}$, to build a country-level measure of the intensity of task $i$ :

$$
\tau_{i c}=\sum_{o} s_{o c} \tau_{i o c}
$$

\footnotetext{
${ }^{3}$ The variation in task content and computer usage is much larger for STEP countries than PIAAC countries. We harmonize each survey question and aggregate them into task categories: non-routine analytical (NRA), non-routine interpersonal (NRI), non-routine manual (NRM), routine cognitive (RC), and routine manual (RM). To assure comparability across occupations and countries, we standardize the task content measures using the US mean and variance. This implies that the distribution of task contents in the US has the same mean 0 and variance 1 in both PIAAC and the US's O*NET. Additional details are in the Data Appendix.

${ }^{4}$ PIAAC and STEP occupation classification is at the 3-digit level.
} 
Table 1: Task Content and GDP Per Capita

\begin{tabular}{lcccccc}
\hline & NRA & NRI & RC & RM & NRM & CU \\
\hline GDP Per Capita & $0.0504^{* * *}$ & $0.0366^{* * *}$ & $-0.0252^{* * *}$ & $-0.0341^{* * *}$ & $-0.00932^{* *}$ & $0.0906^{* * *}$ \\
& $(0.0127)$ & $(0.0110)$ & $(0.00882)$ & $(0.00891)$ & $(0.00437)$ & $(0.0157)$ \\
\hline$N$ & 42 & 42 & 42 & 42 & 42 & 42 \\
$R^{2}$ & 0.282 & 0.218 & 0.169 & 0.268 & 0.102 & 0.454 \\
\hline
\end{tabular}

Note: This table shows the regression results for task intensity on log of GDP per capita in 2015 in each country (WDI).

The first five panels of Figure 1 display the intensity of a given task performed by a country's workers against GDP per capita (PPP in log). For completeness, the last panel plots the intensity of computer usage. The intensity of non-routine tasks in the labor force is positively correlated with income per capita, consistent with the findings in Vizcaino (2019), although non-routine manual tasks have a slight negative correlation. ${ }^{5}$ The magnitude of this correlation is close to zero as shown in Table 1. At the same time, the intensity of routine manual and routine cognitive tasks is negatively correlated with income per capita. This finding differs from Lewandowski et al. (2019) who argue that an inverted- $U$ relationship between routine task intensity and income per capita exists. ${ }^{6}$ A one log-point increase in income is associated with a 5-percent standard deviation increase in the intensity of NRA and a 3.7-percent standard deviation increase in the intensity of NRI. On the flip side, it is associated with a 2.5-percent standard deviation decrease in the RC intensity and a 3.4percent standard deviation decrease in RM. Furthermore, it is associated with a 9-percent standard deviation increase in computer usage.

High-skill workers typically choose occupations that are intensive in non-routine tasks, and low-skill workers choose occupations that are intensive in manual tasks. Therefore, the pattern displayed in Figure 1 is consistent with disparities in the skill composition of the labor force across countries, with a larger share of educated workers in developed economies. However, the correlations between task intensity and income persist, even after controlling for the schooling of the labor force. In fact, all correlations between task intensity and income per capita become stronger once we control for the share of the population with post-secondary education (Table 2). This finding suggests that the correlations between

\footnotetext{
${ }^{5}$ Unlike in Vizcaino (2019), our data allows for within-occupation differences in task intensity across countries.

${ }^{6}$ Lewandowski et al. (2019) maximize STEP and PIAAC comparability to the O*NET assignment, whereas we maximize comparability between STEP and PIAAC. We use the O*NET measures in the US for comparison purposes only. Whereas STEP and PIAAC assessments of task contents are self-reported, those in $\mathrm{O}^{*}$ NET stem from external assessments of the activities for each occupation. Further details of the assignment are in the Data Appendix.
} 
Figure 1: Task Intensity and Development

(a) NRA

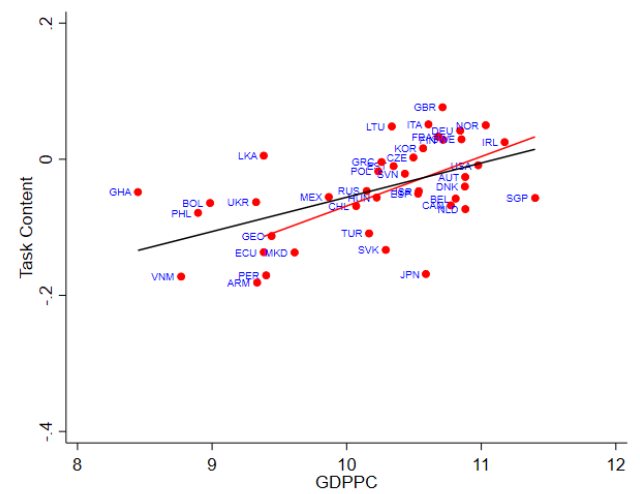

(c) $\mathrm{RC}$

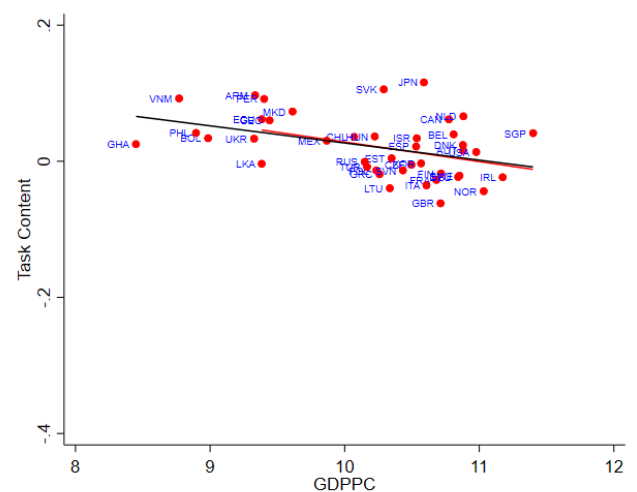

(e) NRM

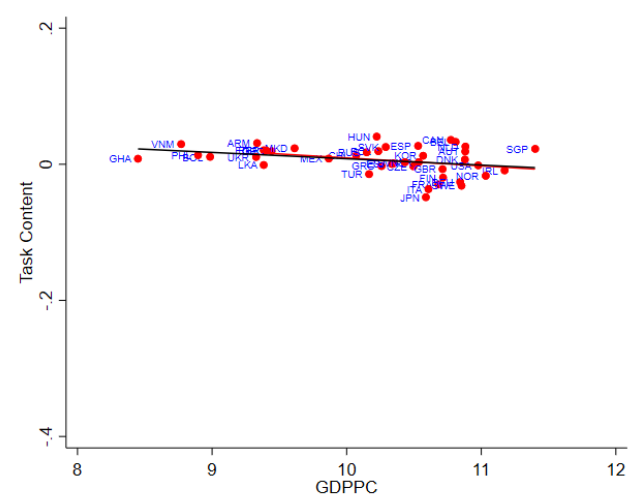

(b) NRI

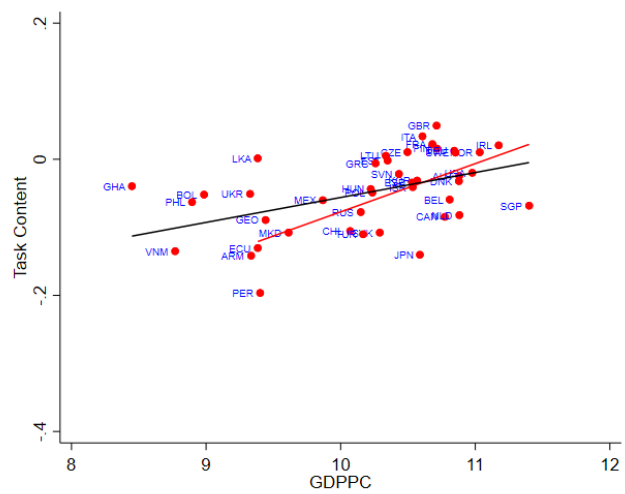

(d) RM

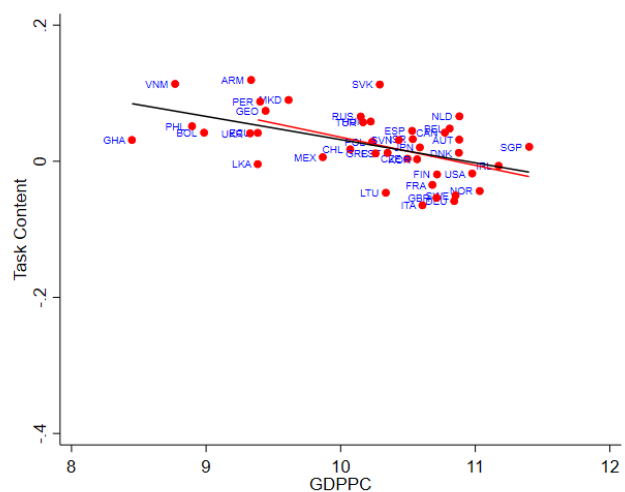

(f) Computer Use

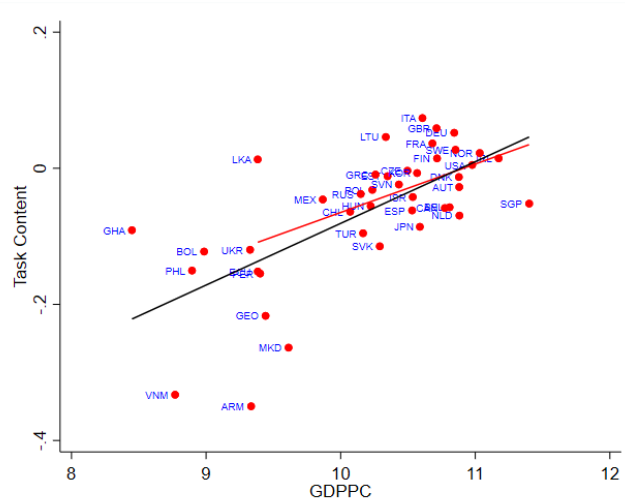

Note: The figure plots the task intensity in a country against its GDP per capita in 2015 (PPP in log) for each of the 5 task category. The black line is the regression line for the full sample that includes the STEP imputation. The red is for the PIAAC sample only. Panel (f) plots computer usage. 
Table 2: Task Content and GDP Per Capita

\begin{tabular}{lcccccc}
\hline & NRA & NRI & RC & RM & NRM & CU \\
\hline Panel A. & & & & & & \\
GDP Per Capita & $0.0712^{* * *}$ & $0.0597^{* * *}$ & $-0.0355^{* *}$ & $-0.0439^{* *}$ & $-0.0140^{*}$ & $0.116^{* * *}$ \\
& $(0.0196)$ & $(0.0172)$ & $(0.0139)$ & $(0.0161)$ & $(0.00751)$ & $(0.0219)$ \\
& & & & & & \\
Post Secondary Education & -0.000104 & -0.000138 & 0.000342 & 0.000269 & 0.000388 & $-0.00210^{*}$ \\
& $(0.00101)$ & $(0.000887)$ & $(0.000717)$ & $(0.000826)$ & $(0.000386)$ & $(0.00113)$ \\
\hline$N$ & 28 & 28 & 28 & 28 & 28 & 28 \\
$R^{2}$ & 0.380 & 0.355 & 0.215 & 0.246 & 0.125 & 0.528 \\
\hline & & & & & & \\
Panel B. & & & & & & \\
GDP Per Capita & $0.0704^{* * *}$ & $0.0586^{* * *}$ & $-0.0328^{* *}$ & $-0.0418^{* * *}$ & -0.0110 & $0.0994^{* * *}$ \\
& $(0.0176)$ & $(0.0155)$ & $(0.0126)$ & $(0.0144)$ & $(0.00688)$ & $(0.0210)$ \\
\hline$N$ & 28 & 28 & 28 & 28 & 28 & 28 \\
$R^{2}$ & 0.380 & 0.355 & 0.208 & 0.243 & 0.090 & 0.463 \\
\hline
\end{tabular}

Note: Panel A shows the regression results of a country's task intensity on its log GDP per capita in 2015, controlling for the share of workers with post secondary education in 2015 (WDI). Education information is available for Armenia, Austria, Belgium, Bolivia, Chile, Czech Republic, Denmark, Ecuador, Finland, France, Germany, Greece, Hungary, Israel, Italy, Korea, Lithuania, Mexico, the Netherlands, Norway, Peru, Singapore, Slovakia, Slovenia, Spain, Sweden, Turkey, USA. Panel B shows the regression results without the education control for this subset of countries.

task intensity and income per capita reflect disparities in the occupational composition of the labor force and/or in the occupational task intensity, rather than disparities in the skill composition of the labor force measured by educational attainment.

A commonly used measure of occupations' task content is the one available from $\mathrm{O}^{*} \mathrm{NET}$ for the US (Autor and Dorn, 2013; Das and Hilgenstock, 2018). ${ }^{7}$ If jobs are similar across countries, one could impute this task content information to the occupational composition of the labor force across countries and construct measures of task intensity as in equation (1). For European countries, Handel (2012) shows that country-specific measures of occupational task contents are similar to $\mathrm{O}^{*} \mathrm{NET}$ measures. However, when studying a broader set of countries this conjecture is rejected. Figure 2 compares the task intensity in each country constructed from our country-specific occupational task contents with the intensity using the common task contents from $\mathrm{O}^{*} \mathrm{NET}$. By construction, the variation across countries in the latter are only due to differences in the occupational composition of the labor force.

The correlation between non-routine analytical intensity and income per capita is similar whichever measure of task intensity we use. These patterns suggest that most of the positive correlation between the non-routine analytical intensity and income across countries is driven

\footnotetext{
${ }^{7}$ The Dictionary of Occupational Titles (DOT) is the precursor to the O*NET.
} 
Figure 2: Task Content Decomposition and Development
(a) NRA
(b) NRI
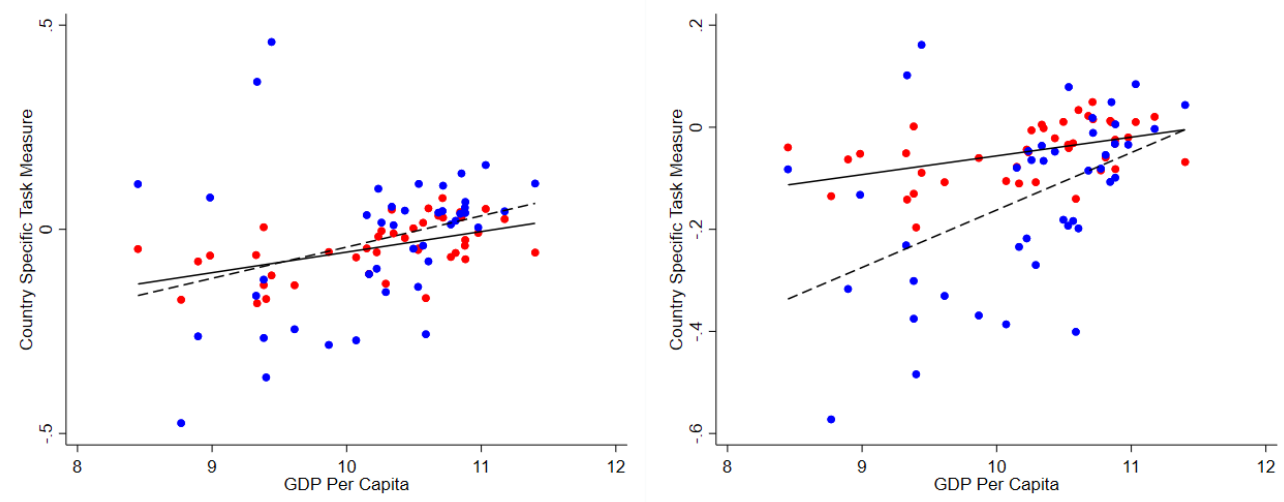

(c) $\mathrm{RC}$

(d) RM
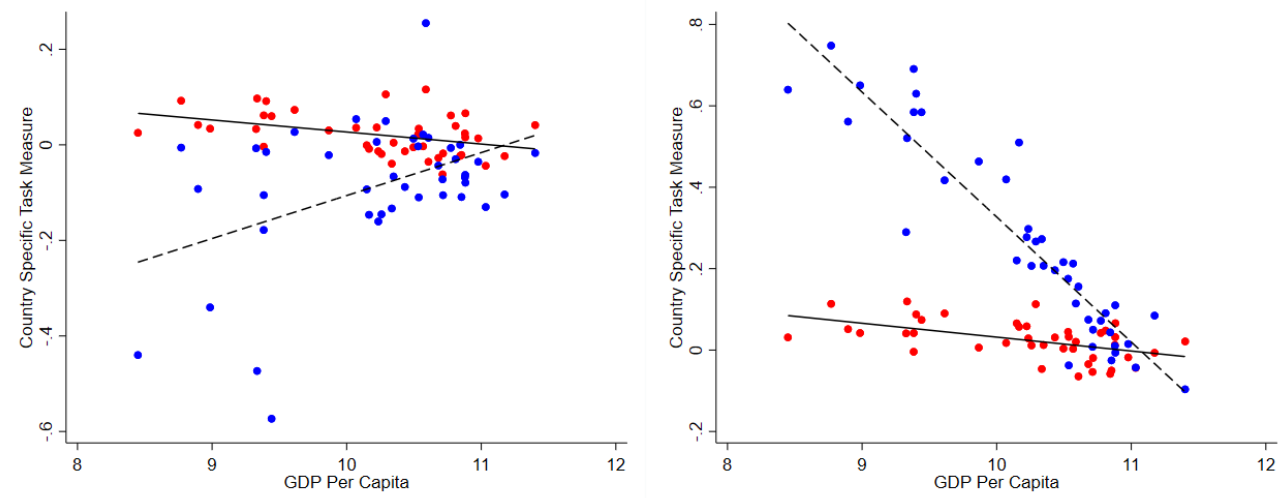

(e) NRM

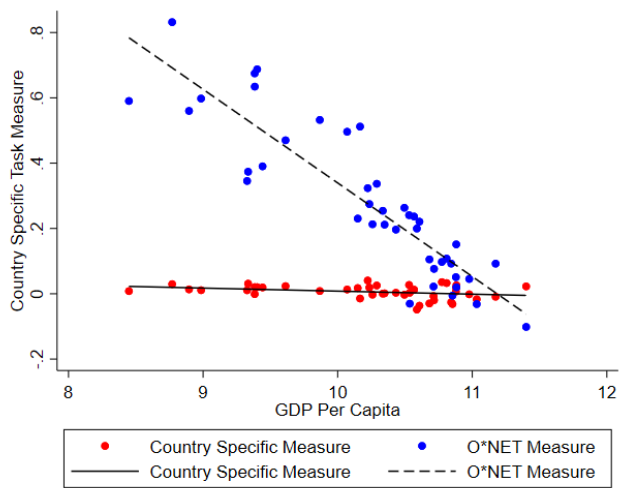

Note: This figure plots a country's task intensity based on country-specific (red) and O*NET-based (blue) measures of occupational task contents against GDP per capita (PPP in log). The solid line is the correlation between GDP and task intensity based on country-specific occupational task contents. The dashed line is the correlation between GDP and task intensity based on O*NET. 
by the occupational composition of the labor force - for example, the share of managers and professionals in the labor force is smaller in developing countries. For non-routine interpersonal, the positive slope of the dashed line shows that developing countries have fewer workers in the NRI-intensive occupations, but the flatter solid line implies that a given occupation in developing countries is more NRI-intensive than the same occupation in developed countries.

For manual tasks and routine cognitive tasks, the correlations between task intensity and income are substantially different between the two measures. When we use the O*NETbased measures, the negative correlation between manual intensity (RM, NRM) and income is stronger than when using country-specific occupational task contents. In other words, poor countries have disproportionately more workers in manual-intensive occupations (this is why the dashed line has a steep negative slope), but those occupations involve less manual contents in poor countries than in the US (this is why the solid line is flatter than the dashed line). For routine cognitive tasks, the correlation is also stronger when using $\mathrm{O}^{*}$ NET measures but in the opposite direction. A log point increase in income per capita is associated with a 9-percent standard deviation increase in the routine cognitive intensity when using $\mathrm{O}^{*} \mathrm{NET}$ (Table 6 in the Appendix), and a 2.5-percent decrease when using country-specific measures. Hence, developing countries have disproportionately less workers in routine-cognitive intensive occupations (this is why the dashed line slopes upward), but those occupations involve a lot more routine-cognitive tasks in developing countries than in developed economies, so much so that the solid line slopes downward.

The patterns uncovered for routine-manual and routine-cognitive tasks are particularly relevant for assessing the impact of technological change on labor allocation across the development spectrum. On the one hand, developing countries tend to have larger fractions of workers in routine-manual occupations, exactly those that could be automated easily (Autor and Dorn, 2013). However, those occupations are less intensive in routine-manual tasks in developing countires than in developed economies, making them harder to automate. Routine-cognitive tasks are also more prone to automation. However, developing countries have relatively small fraction of their labor force engaged in these occupations, although the RC intensity of a given job is higher in developing countries. In sum, the exposure to technologies that can replace routine-intensive jobs does not seem to vary much with income, when the occupational task intensity is measured at the country level.

To further investigate the role of cross-country disparities in the occupational composition of the labor force and the task content of occupations, we decompose the differences in county-level task intensity as follows. Let the average task content $(i)$ across countries of 
occupation $o$ be $\bar{\tau}_{i o}$ and the average employment share across countries of occupation $o$ be $\bar{s}_{o}$. Differences across countries in the intensity of task $i$ relative to the cross-country mean, $\sum_{o}\left(\tau_{i c o} s_{c o}-\bar{\tau}_{i o} \bar{s}_{o}\right)$, can be decomposed into differences in task contents within an occupation (task effect), differences in the allocation of workers to a given occupation relative to the average (employment effect), and the correlation between the within occupation task contents and their employment allocation across countries (cross effect).

$$
\sum_{o}\left(\tau_{i c o} s_{c o}-\bar{\tau}_{i o} \bar{s}_{o}\right)=\underbrace{\sum_{o}\left(\tau_{i c o}-\bar{\tau}_{i o}\right) \bar{s}_{o}}_{\text {task effect }}+\underbrace{\sum_{o} \bar{\tau}_{i o}\left(s_{c o}-\bar{s}_{o}\right)}_{\text {employment effect }}+\underbrace{\sum_{o}\left(\tau_{i c o}-\bar{\tau}_{i o}\right)\left(s_{c o}-\bar{s}_{o}\right)}_{\text {cross effect }}
$$

For each country in our sample we compute the differential in task intensity from the mean and each of the three components. We correlate these components with countries' income per capita, and the results are reported in Table 3. The reported coefficients are broadly consistent with the regression lines shown in Figure 2. For non-routine analytical and non-routine interpersonal, developing countries have fewer workers in the occupations that use these tasks intensively (a positive employment share coefficient) than do developed countries, but a given occupation in developing countries uses these tasks more intensively than the same occupation in developed countries (a negative task content term). It is exactly the opposite for routine-manual and nonroutine-manual intensity. For routine cognitive, the coefficient on the employment share and the task content seem opposite of what is suggested by Figure 2. One explanation for this inconsistency is that Figure 2 is a comparison between country-specific task intensities relative to the O*NET-based intensities of the US, while what is shown in the table comes from the variation in country-specific task intensities across countries. Such divergence is possible if the $\mathrm{O}^{*}$ NET intensities are an outlier in the intensity-income relationship. We also see that some of the cross terms are significant, but they are smaller in magnitude than the other two terms.

The analysis in this section emphasizes the need to measure occupation-level task contents for each country, which turn out to vary systematically across the development spectrum. One implication is that the question of why occupation-level task contents vary across countries should be addressed jointly with the question of why employment across occupations vary across countries. 
Table 3: Task Content Decomposition and Development

\begin{tabular}{|c|c|c|c|}
\hline & Task Content & Employment Share & Cross Term \\
\hline \multicolumn{4}{|c|}{ Non-Routine ANALYTIC: } \\
\hline \multirow[t]{2}{*}{ log(GDP Per Capita) } & $-0.121^{* * *}$ & $0.179^{* * *}$ & $-0.0193^{* *}$ \\
\hline & $(0.0182)$ & $(0.0195)$ & $(0.00805)$ \\
\hline$R^{2}$ & 0.524 & 0.678 & 0.125 \\
\hline \multicolumn{4}{|c|}{ NON-ROUTINE INTERPERSONAL: } \\
\hline \multirow[t]{2}{*}{$\log ($ GDP Per Capita) } & $-0.0919^{* * *}$ & $0.150^{* * *}$ & $-0.0162^{*}$ \\
\hline & $(0.0146)$ & $(0.0162)$ & $(0.00849)$ \\
\hline$R^{2}$ & 0.499 & 0.682 & 0.083 \\
\hline \multicolumn{4}{|l|}{ Routine Cognitive: } \\
\hline \multirow{2}{*}{$\log ($ GDP Per Capita $)$} & $0.0544^{* * *}$ & $-0.0776^{* * *}$ & 0.00143 \\
\hline & $(0.0111)$ & $(0.0128)$ & $(0.00803)$ \\
\hline$R^{2}$ & 0.375 & 0.480 & 0.001 \\
\hline \multicolumn{4}{|l|}{ RoUtine MANUAL: } \\
\hline \multirow[t]{2}{*}{$\log ($ GDP Per Capita) } & $0.0760^{* * *}$ & $-0.201^{* * *}$ & $0.0550^{* * *}$ \\
\hline & $(0.0151)$ & $(0.0150)$ & $(0.00812)$ \\
\hline$R^{2}$ & 0.387 & 0.818 & 0.534 \\
\hline \multicolumn{4}{|c|}{ Non-Routine Manual: } \\
\hline \multirow[t]{2}{*}{$\log ($ GDP Per Capita) } & $0.0173^{*}$ & $-0.0634^{* * *}$ & $0.0185^{* *}$ \\
\hline & $(0.00875)$ & $(0.00571)$ & $(0.00698)$ \\
\hline$R^{2}$ & 0.089 & 0.755 & 0.149 \\
\hline
\end{tabular}




\subsection{Gender Disparities}

The systematic cross-country differences in task intensity we document hide substantial heterogeneity across workers from different skill and demographic groups within each country. To illustrate this heterogeneity we focus on one characteristics of the worker: gender. Our choice is motivated by the documented link between the labor market prospects for women and structural change, in relation to sectoral differences in task contents (Lee and Wolpin, 2006; Rendall, 2010; Goldin and Katz, 2012; Goldin, 2014; Ngai and Petrongolo, 2017). In this section, we document how the differences in the tasks performed by males and females vary across the development spectrum and investigate its main drivers.

For each task $i$, we define the gender task differential as the sum across occupations of the country-specific task intensity of the occupation (common for men and women) multiplied by the difference between the female $f$ and male $m$ employment shares:

$$
\sum_{o}\left(\tau_{i c o} \Delta^{g} s_{c o}\right), \quad \text { with } \Delta^{g} s_{c o} \equiv s_{c o}^{f}-s_{c o}^{m},
$$

where $\Delta^{g} s_{c o}$ is the gender difference in the employment share of occupation $o$ in country $c$. Figure 3 plots the gender differentials in task intensity against GDP per capita (PPP in log) for each task. We divide countries into three groups based on their GDP per capita, with low-income countries in the lowest quartile, high-income countries in the highest quartile, and middle-income countries in the second and the third quartiles. For non-routine analytical and non-routine interpersonal tasks, the gender differential has an inverted- $U$ shape against countries' income levels. There is a positive association between income per capita and the gender task differential among low-income countries but a negative one among middleand high-income countries. On the other hand, the gender differential for routine cognitive, routine manual and non-routine manual tasks is $U$-shaped across countries. In low- and highincome countries, women tend to perform more routine cognitive and non-routine manual tasks than men, while in middle-income countries the opposite is true.

These patterns in the gender task differentials across countries are driven by gender differences in occupational choices across countries. Men and women tend to choose different occupations in all countries, due to skill endowment differences (Galor and Weil, 1996; Rendall, 2010) or labor-market distortions that impact men and women differently (Fernández et al., 2004; Hsieh et al., 2019). ${ }^{8}$ In addition, the gender task differential varies across countries even when gender differences in occupational choice were identical across countries, as

\footnotetext{
${ }^{8}$ These two channels are important determinants of the gender gap in occupational choices in the US (Hsieh et al., 2019) and can, at the same time, partly account for the evolution of the US occupational employment.
} 
Figure 3: Gender Task Differential and Development

(a) NRA

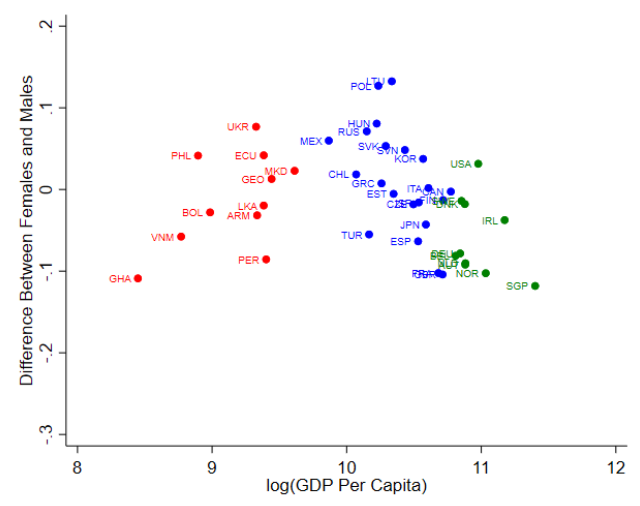

(c) $\mathrm{RC}$

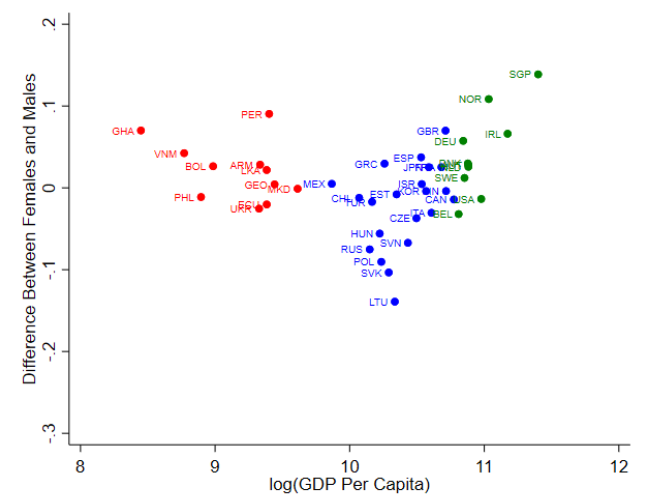

(b) NRI

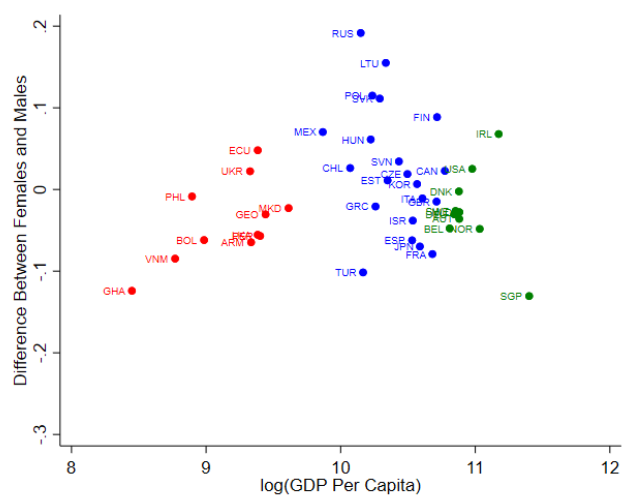

(d) RM

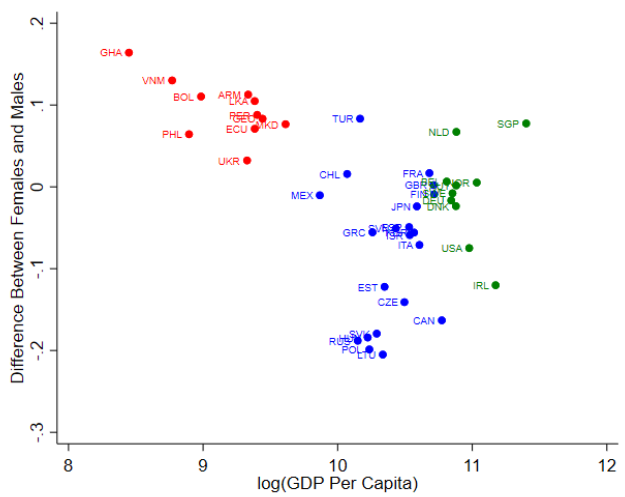

(e) NRM

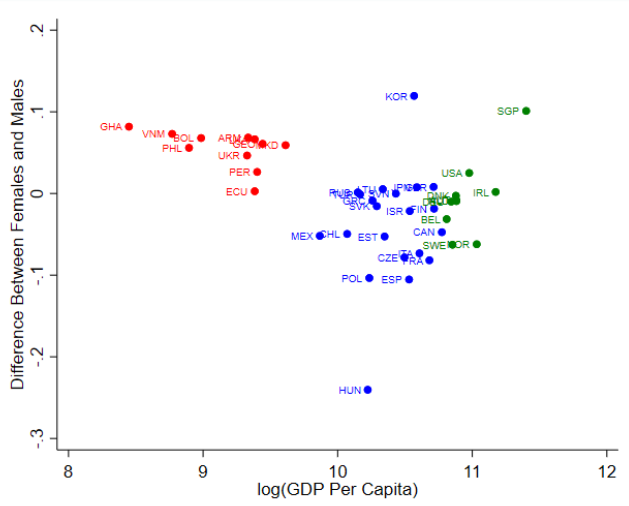

The figure plots the gender task intensity differential against GDP per capita (PPP in log) in 2015. Countries are divided into three groups based on their income: low-income countries have 2015 PPP GDP per capita in the lowest income quartile (red), high-income countries in the highest quartile (green), and middle-income countries are in the second and the third quartiles (blue). 
long as the occupational task contents vary across countries, as we show to be the case in Section 3.1. We assess the role of each of these two effects with a decomposition exercise.

We take the average across the countries in our sample and decompose the difference in the gender differential in task $i$ between country $c$ and this average into three components:

$$
\begin{aligned}
\sum_{o}\left(\tau_{i c o} \Delta^{g} s_{c o}-\bar{\tau}_{i o} \Delta^{g} \bar{s}_{o}\right)= & \sum_{o} \bar{\tau}_{i o}\left(\Delta^{g} s_{c o}-\Delta^{g} \bar{s}_{o}\right)+\sum_{o} \Delta^{g} \bar{s}_{o}\left(\tau_{i c o}-\bar{\tau}_{i o}\right)+ \\
& \sum_{o}\left(\Delta^{g} s_{c o}-\Delta^{g} \bar{s}_{o}\right)\left(\tau_{i c o}-\bar{\tau}_{i o}\right),
\end{aligned}
$$

where $\bar{\tau}_{i o}$ is the cross-country average of task $i$ intensity in occupation $o$ and $\Delta^{g} \bar{s}_{o}$ is the cross-country average of the gender difference in employment share in occupation $o$. The first term on the right-hand side is the role of gender differences in occupational choices that vary across countries, for a given structure of occupational task contents (employment effect). The second term is the role of occupational differences in the task contents across countries, for a given gender difference in occupational choices between women and men (task effect). The last term is the cross effect.

Table 4: Decomposition of the Gender Task Differential (1)

\begin{tabular}{lrrr}
\hline & Employment effect & Task effect & Cross effect \\
\hline Non-routine analytical & $66.0 \%$ & $20.1 \%$ & $13.9 \%$ \\
Non-routine interpersonal & $52.2 \%$ & $29.0 \%$ & $18.8 \%$ \\
Routine cognitive & $40.9 \%$ & $42.0 \%$ & $17.1 \%$ \\
Routine manual & $46.9 \%$ & $47.8 \%$ & $5.4 \%$ \\
Non-routine manual & $23.2 \%$ & $70.0 \%$ & $6.8 \%$ \\
\hline
\end{tabular}

Note: The table shows what fraction of the cross-country variation in gender task intensity differential is accounted for by each of the three terms in the decomposition equation (3).

Table 4 summarizes the results of the decomposition across countries, for the five task categories in our analysis. The employment effect is most important in explaining the crosscountry differences in the gender task differential for non-routine analytical and non-routine interpersonal, explaining 66 and 52 percent, respectively. Instead, the task effect is most important in explaining the gender differential for non-routine manual, of which it explains 70 percent. Both effects are equally important in explaining the cross-country variation in the gender differential for routine cognitive and routine manual tasks. The cross term is less important.

Next, we study the contribution of each effect to the patterns of gender task differentials across the development spectrum. Table 5 reports the coefficients from regressing the gender 
Table 5: Decomposition of the Gender Task Differential (2)

\begin{tabular}{|c|c|c|c|c|c|c|c|c|}
\hline & Total-L & Total-MH & Task-L & Task-MH & Empl.-L & Empl.-MH & Cross-L & Cross-MH \\
\hline \multicolumn{9}{|c|}{ NON-ROUTINE ANALYTICAL: } \\
\hline $\log ($ GDP Per Capita) & $\begin{array}{c}0.0814 \\
(0.0468)\end{array}$ & $-0.127^{* * *}$ & $\begin{array}{c}0.0266 \\
(0.0151)\end{array}$ & $-0.0547^{* * *}$ & $\begin{array}{c}0.0671 \\
(0.0573)\end{array}$ & $\begin{array}{l}-0.0436 \\
(0.0265)\end{array}$ & $\begin{array}{l}-0.0123 \\
(0.0232)\end{array}$ & $\begin{array}{c}-0.0288^{* * *} \\
(0.00695)\end{array}$ \\
\hline$R^{2}$ & 0.252 & 0.424 & 0.256 & 0.340 & 0.132 & 0.086 & 0.030 & 0.372 \\
\hline \multicolumn{9}{|c|}{ NON-ROUTINE INTERPERSONAL: } \\
\hline $\log ($ GDP Per Capita) & $\begin{array}{l}0.0808^{*} \\
(0.0370)\end{array}$ & $\begin{array}{c}-0.0976^{* * *} \\
(0.0347)\end{array}$ & $\begin{array}{l}0.0299^{*} \\
(0.0144)\end{array}$ & $\begin{array}{l}-0.0286 \\
(0.0170)\end{array}$ & $\begin{array}{l}-0.0134 \\
(0.0471)\end{array}$ & $\begin{array}{l}-0.0395 \\
(0.0243)\end{array}$ & $\begin{array}{l}0.0643^{* *} \\
(0.0252)\end{array}$ & $\begin{array}{r}-0.0296^{* * *} \\
(0.00821)\end{array}$ \\
\hline$R^{2}$ & 0.346 & 0.215 & 0.323 & 0.089 & 0.009 & 0.083 & 0.420 & 0.309 \\
\hline $\begin{array}{l}\text { Routine COGNitive: } \\
\text { log(GDP Per Capita) }\end{array}$ & $\begin{array}{l}-0.0391 \\
(0.0319)\end{array}$ & $\begin{array}{l}0.110^{* * *} \\
(0.0240)\end{array}$ & $\begin{array}{r}-0.00900 \\
(0.0134)\end{array}$ & $\begin{array}{l}0.0394^{* *} \\
(0.0185)\end{array}$ & $\begin{array}{c}-0.0593 \\
(0.0362)\end{array}$ & $\begin{array}{l}0.0341^{* *} \\
(0.0157)\end{array}$ & $\begin{array}{c}0.0292 \\
(0.0234)\end{array}$ & $\begin{array}{l}0.0369^{* * *} \\
(0.00537)\end{array}$ \\
\hline$R^{2}$ & 0.143 & 0.421 & 0.048 & 0.135 & 0.230 & 0.140 & 0.148 & 0.620 \\
\hline \multicolumn{9}{|l|}{ ROUTINE MANUAL: } \\
\hline $\log$ (GDP Per Capita) & $\begin{array}{c}-0.0646^{* *} \\
(0.0256)\end{array}$ & $\begin{array}{l}0.0859^{* *} \\
(0.0413)\end{array}$ & $\begin{array}{l}-0.0300 \\
(0.0175)\end{array}$ & $\begin{array}{c}0.0464^{* * *} \\
(0.0162)\end{array}$ & $\begin{array}{l}-0.0626 \\
(0.0568)\end{array}$ & $\begin{array}{l}0.0276 \\
(0.0242)\end{array}$ & $\begin{array}{c}0.0280 \\
(0.0294)\end{array}$ & $\begin{array}{c}0.0119 \\
(0.0108)\end{array}$ \\
\hline$R^{2}$ & 0.415 & 0.130 & 0.248 & 0.220 & 0.119 & 0.043 & 0.092 & 0.040 \\
\hline \multicolumn{9}{|l|}{ NON-ROUTINE MANUAL: } \\
\hline $\log ($ GDP Per Capita $)$ & $\begin{array}{l}-0.0321 \\
(0.0186)\end{array}$ & $\begin{array}{l}0.0644^{* *} \\
(0.0314)\end{array}$ & $\begin{array}{l}-0.0208 \\
(0.0166)\end{array}$ & $\begin{array}{c}0.0273 \\
(0.0227)\end{array}$ & $\begin{array}{l}-0.0234 \\
(0.0252)\end{array}$ & $\begin{array}{l}0.0219^{*} \\
(0.0109)\end{array}$ & $\begin{array}{c}0.0121 \\
(0.0197)\end{array}$ & $\begin{array}{c}0.0151 \\
(0.00904)\end{array}$ \\
\hline$R^{2}$ & 0.249 & 0.127 & 0.148 & 0.047 & 0.087 & 0.122 & 0.040 & 0.088 \\
\hline
\end{tabular}

Note: This table shows the outcomes from regressing the variables on the columns on GDP per capita (PPP in $\log$ ) in 2015 and an intercept. The column labels Total, Task, Empl. and Cross represent the gender task differential, the task effect, the employment effect, and the cross effect, respectively. We only report the coefficients on GDP per capita (standard errors are in parentheses) and the $R^{2}$. Countries are divided into two groups, with low-income countries (L) in the lowest income per capita quartile, and middle- and high-income countries $(\mathrm{MH})$ in the other 3 quartiles.

task differential and its decomposition components on GDP per capita (PPP in log). We run the regressions separately for low-income countries and middle-to-high income countries to accommodate the non-monotonic relationship between the task differential and income in Figure 3.

Overall, and focusing only on the statistically significant cefficients, the task effect is more important than the other effects for generating the association between gender differential in task intensity and income for both groups of countries. In particular, among middle- and high-income countries, the task effect is the most important in explaining the covariation of non-routine analytical and routine manual task gender differential with income. For routine cognitive and non-routine interpersonal, all three effects have similar magnitudes, even though GDP per capita accounts for a higher fraction of the statistical variation in the cross effect. Turning to low-income countries, the smaller sample size implies fewer 
significant results. The task effect is important in explaining the covariation of non-routine interpersonal task gender differential together with the cross effect, and GDP per capita accounts for a significant fraction of the statistical variation in both effects.

The findings above document the quantitative relevance of the task effect, along with the employment effect. The task effect has been mostly ignored in previous studies, which assumed identical occupational task contents across countries, due to data limitations. How would our findings on the gender task differential change if, instead of measuring occupational task contents for each country, we assumed all countries have the same occupation-level task contents? Figure 4 plots countries' gender differentials in task contents under this alternative computation, fixing all occupational task contents at the US levels from O*NET. Comparing Figures 3 and 4, we see that the alternative computation results in more variation in the gender task differential among poor countries. As a consequence, we would have inferred no consistent variation across the development spectrum for all tasks but routine cognitive. Focusing on middle- and high-income countries, the direction of the relationships between gender differential in task intensity and income is consistent between the two computations, but its strength is not. For non-routine analytical and routine cognitive the slope of the regression line on GDP per capita (PPP in log) decreases by 23 and 32 percent in the alternative computation, respectively. In addition, the positive correlation between gender differential and GDP per capita for routine manual and non-routine manual tasks becomes statistically insignificant in the alternative computation. In summary, the country-specific occupational content helps uncover the systematic relationship between gender task differential and a country's income level. It shows that when exploring the cross-country difference in the occupational employment of men and women, one also needs to consider the fact that occupation-level tasks vary across countries systematically across the development spectrum.

\section{Changes in Task Intensity over Time}

Technological change can replace workers with machines in certain tasks and reallocate workers to other tasks, including new ones. As defined in Section 2, the exposure of labor to technological change is the response of labor demand to technological change. From the data, and in the absence of information about the supply side, we infer the shift in demand for labor from the change in overall task intensity of the labor market over time. Using the task content of occupations across countries constructed in Section 3, we examine the direction of technological change and its relationship with the initial composition of the labor force. We look into the allocation of labor across both occupations and sectors. 
Figure 4: Gender Task Differential and Development Based on O*NET.

(a) NRA

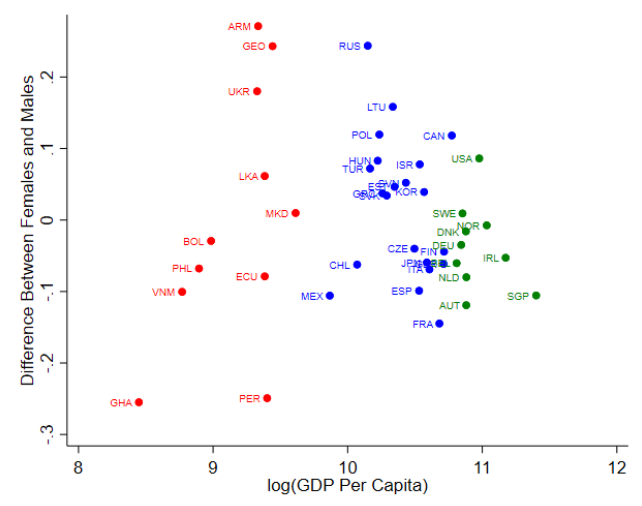

(c) $\mathrm{RC}$

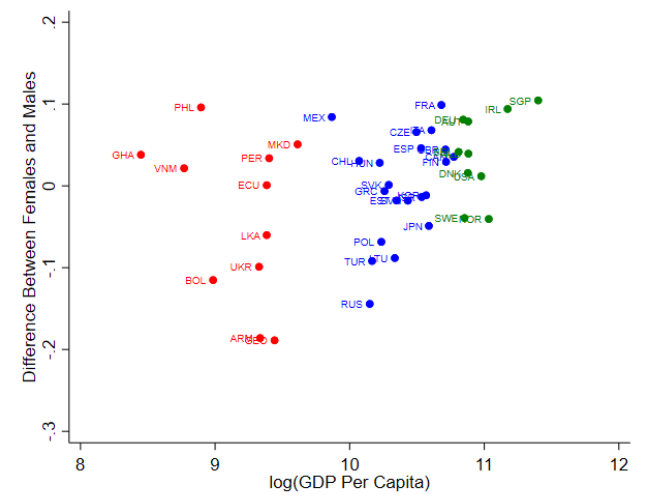

(b) NRI

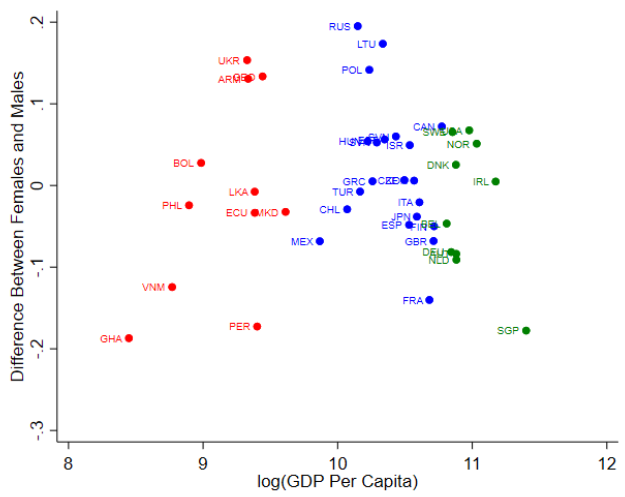

(d) RM

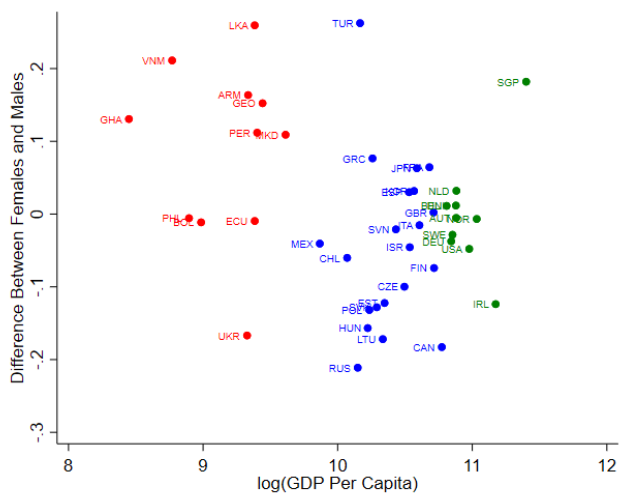

(e) NRM

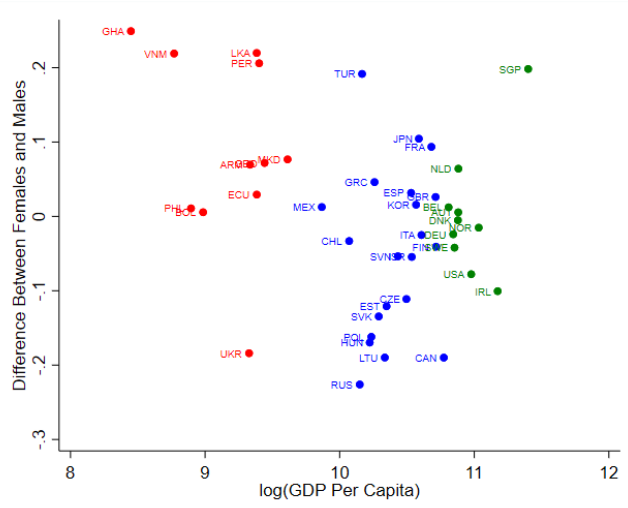

Note: The figure plots, for each task, the gender tasks differential computed using O*NET data for the US against GDP per capita (PPP in log) in 2015. Countries are divided into three groups based on their income: low-income countries in the lowest income quartile (red), high-income countries in the highest income quartile (green), and middle-income countries in the second and the third income quartile (blue). 


\subsection{Role of Occupational Employment Changes}

We have seen how the tasks that workers perform, as defined by equation (1), vary across the development spectrum at a point in time. In developed countries workers perform more nonroutine analytical and interpersonal tasks and less routine tasks than in developing countries. As reviewed in Section 2, since 1980, developed countries have experienced clear patterns of polarization and de-routinization, or the loss of middle-skill, routine-intensive jobs. The pattern for developing countries is less clear, and the small literature on this topic reached conflicting conclusions, depending on whether or not the task content of occupations was assumed to be the same across countries.

We now use our country-specific measure of the task contents of occupations to quantify the changes in task intensity over time for each country in our sample. Note that the countryspecific task contents of occupations are fixed over time, so any change in country-level task intensity comes from the shifts in the occupational composition of the labor force.

Figure 5 plots the change in overall task intensity of a country between 2006 and 2015 against its GDP per capita (PPP in log) in 2006. For all five task categories, there is no clear relationship between a country's income level and the changes in its task intensity between 2006 and 2015. We even do not see a significant drop in routine task intensity for developed countries, seemingly at odds with the polarization literature. This is due to the sample period difference: For our cross-country comparison, our sample period is 2006-2015. The literature on developed countries looks at an earlier, longer period starting in 1980, and reports a slowing pace of polarization since 2000 (Beaudry et al., 2016). The lack of a clear trend for developing countries fits into the wide range of findings in the literature. ${ }^{9}$

Conspicuous patterns emerge if we plot the change in overall task intensity of a country between 2006 and 2015 against its initial intensity in 2006. As shown in Figure 6, for all five task categories, the countries with high intensity in 2006 experienced rapid reductions in these intensities, as the occupations that use these tasks intensively shrank. In other words, there has been some convergence in country-level task intensities. We also note that, for the vast majority of countries, the intensities of routine cognitive, routine manual and non-routine manual tasks decreased (negative change). On the other hand, in the majority of countries, non-routine analytical task intensity increased. These patterns suggest that the technological change between 2006 and 2015 was indeed in the direction of replacing

\footnotetext{
${ }^{9}$ Although not shown here, no pattern emerges when we measure the task contents of occupations based on the US O*NET and assume they are the same across all countries. The difference between this result and the findings from the similar approach in the literature can be attributed to the difference in the sample coverage.
} 
Figure 5: Task Intensity Change and GDP per Capita, Country-specific Task Measure

(a) NRA

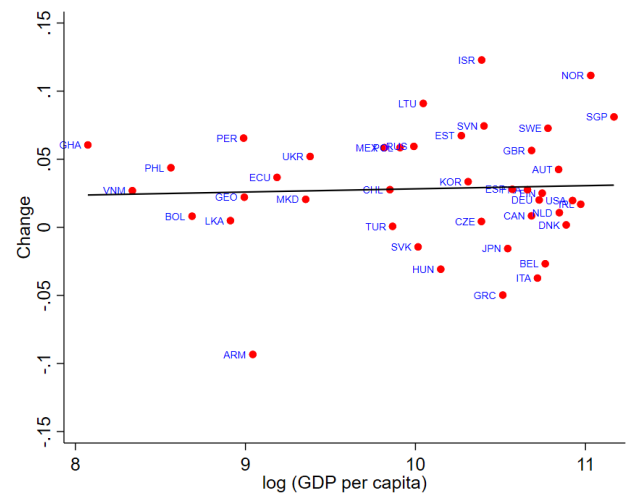

(c) $\mathrm{RC}$

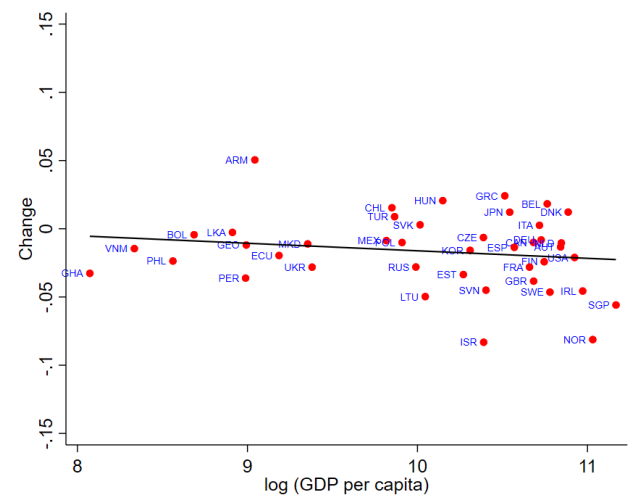

(b) NRI

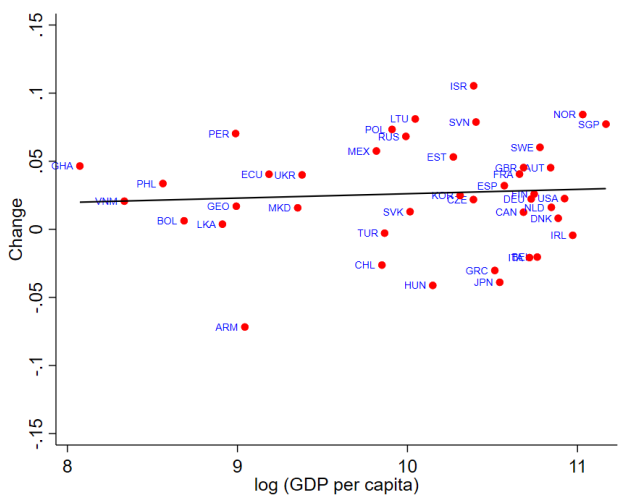

(d) RM

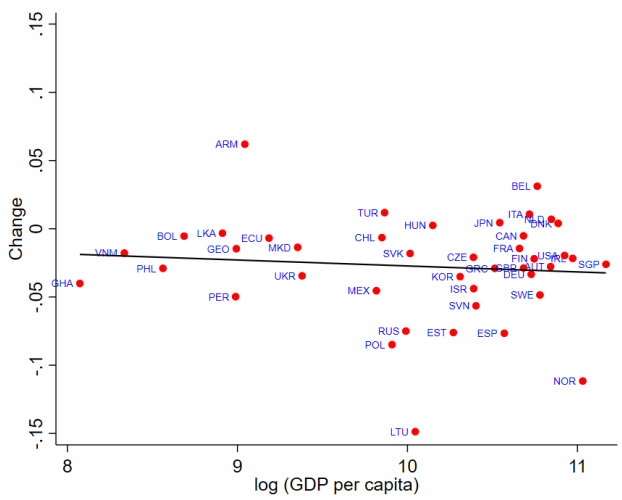

(e) NRM

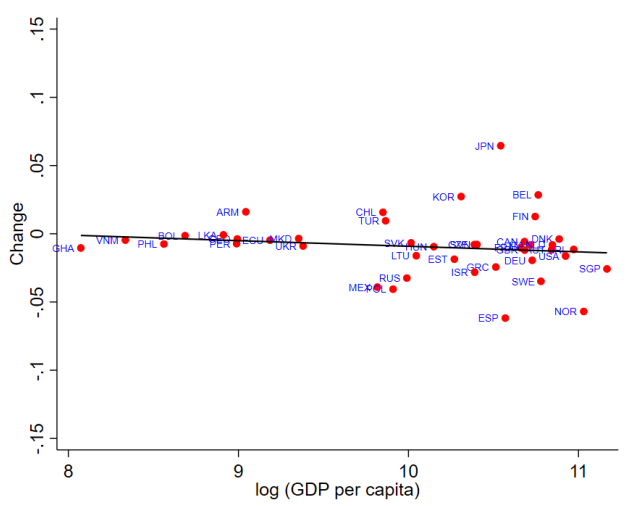

Note: This figure shows the change in countries' task intensity between 2006 and 2015 against the log GDP per capita in 2006 for each country. The change in task intensity is solely accounted for by the occupational employment changes between 2006 and 2015, because occupational task content is country-specific but fixed over time. GDP per capita is PPP and is from the World Development Indicators (WDI). 
Figure 6: Task Intensity Change and Task Intensity in 2006, Country-specific Task Measure

(a) NRA

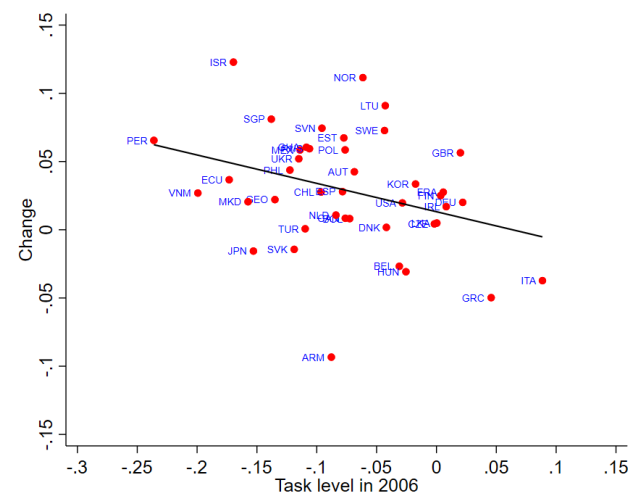

(c) $\mathrm{RC}$

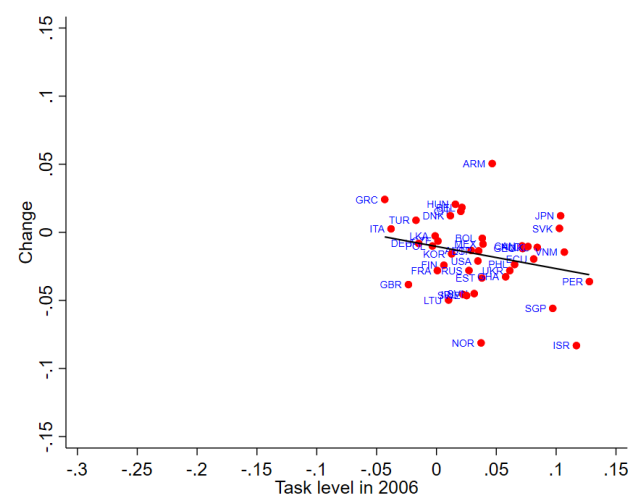

(b) NRI

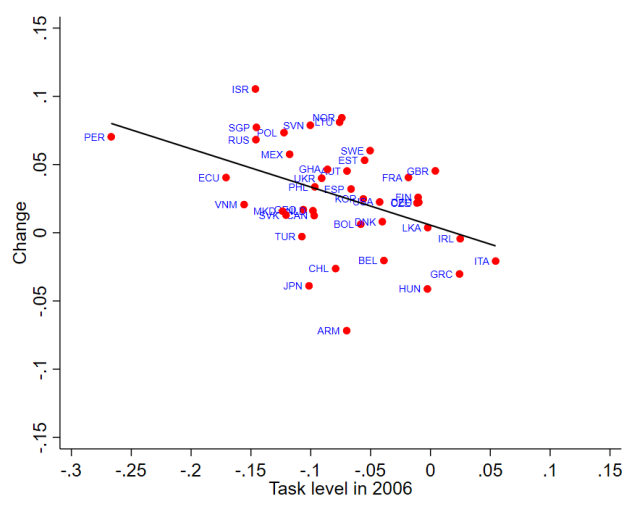

(d) RM

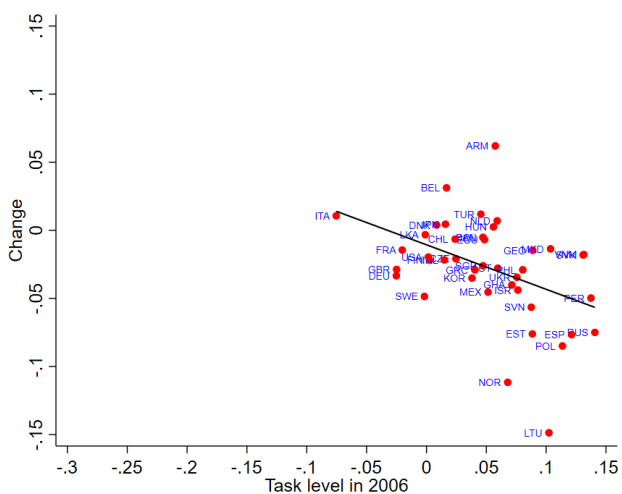

(e) NRM

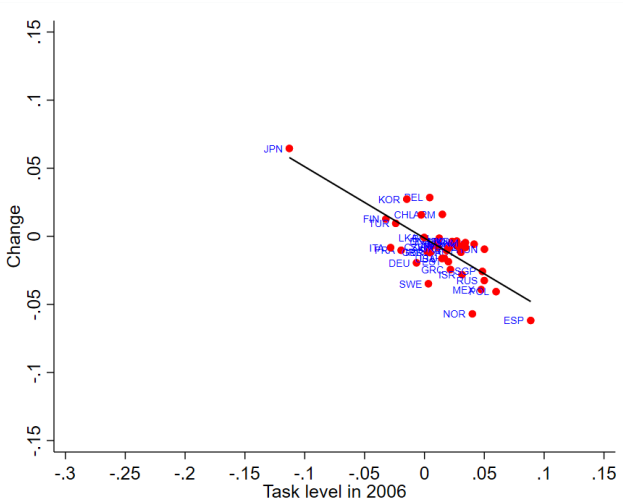

Note: This figure shows the change in task intensity between 2006 and 2015 against the task intensity in 2006 for each country. The change in task intensity is solely accounted for by the occupational employment changes between 2006 and 2015, because occupational task content is country-specific but fixed over time. 
routine-intensive jobs and complementing analytical jobs.

We repeat the exercise but now use occupational task contents that are common across countries, based on the US O*NET classification. The results remain largely unchanged, except that now non-routine interpersonal intensity appears to have gone up significantly in most countries. (See Figure 8 in the appendix.)

In summary, how a country's labor allocation will be affected by technological change can be better predicted by its occupational task content and employment shares, rather than its income level.

\subsection{Role of Employment Reallocation across Sectors}

For each country, occupational task contents are defined and measured at a point in time. As a result, the changes in task intensity over time are the result of the changing employment across occupations over time. Our view is that such changes in occupational employment are driven by technological change at the level of tasks and occupations. However, because most countries are undergoing structural change, it is possible that the occupational employment changes are driven by sector-specific technological change that reallocates workers across sectors: the occupations over-represented in expanding sectors will gain employment, and those over-represented in shrinking sectors will lose employment. ${ }^{10}$

We assess, albeit indirectly, the relative importance of occupation-specific and sectorspecific technological change for occupational employment changes using the following decomposition.

First, the employment share of occupation $o$ in period $t$ is defined as

$$
s_{o t} \equiv \sum_{j \in J} \frac{l_{o j t}}{l_{j t}} \times \frac{l_{j t}}{l_{t}},
$$

where $l_{o j t}$ is the number of workers in occupation $o$ in sector $j$ in year $t, l_{j t}$ is the number of workers in sector $j$ in year $t$, and $J$ is the set of sectors. The employment share change of occupation $o$ from year $s$ to $t$ can be written as

$$
\Delta s_{o t}=\underbrace{\sum_{j \in J} \Delta\left(\frac{l_{o j t}}{l_{j t}}\right) \times \overline{\left(\frac{l_{j}}{l}\right)}}_{\text {within sector }}+\underbrace{\sum_{j \in J} \Delta\left(\frac{l_{j t}}{l_{t}}\right) \times \overline{\left(\frac{l_{o j}}{l_{j}}\right)}}_{\text {between sector }},
$$

\footnotetext{
${ }^{10}$ This compositional link between occupations and structural change accords with Lee and Shin (2017) but differs from that in Duernecker and Herrendorf (2016), who classify occupations based on the goods they are likely to produce.
} 
Figure 7: Decomposition of Occupational Employment Change: Within-industry Component

(a) 1-digit Industry

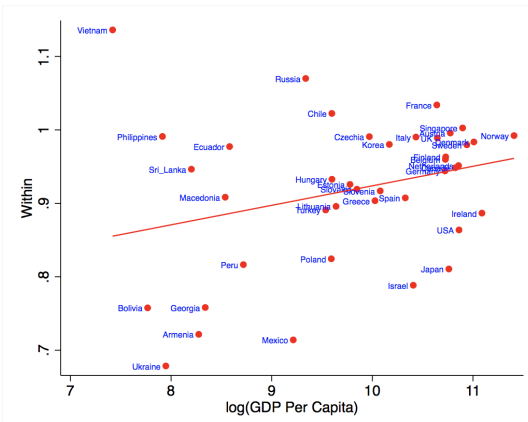

(b) 2 Sectors

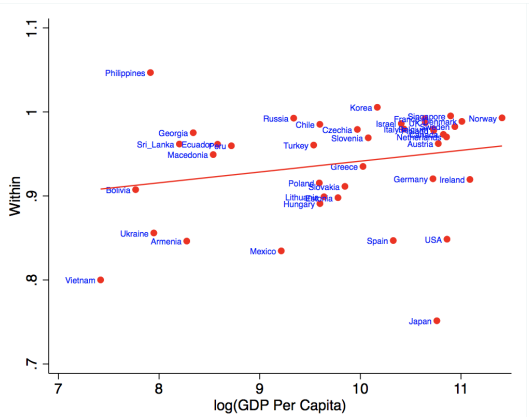

(c) 3 Sectors

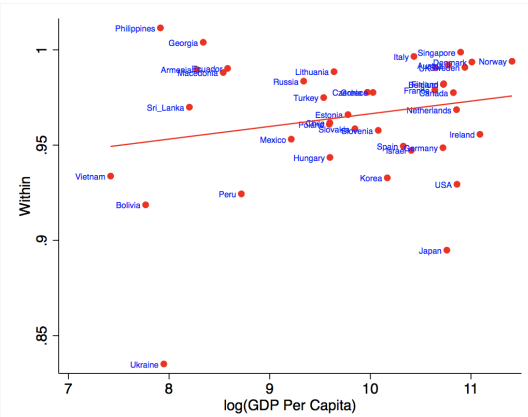

Note: This figure shows the within-industry component of the changes in occupational employment share between 2006 and 2015 for each country. 1 minus the within-industry component is the between-industry component, i.e., the change in occupational employment share due to the changes in industrial employment share. There are 9 1-digit occupations. In the left panel, we use 19 industries in the 1-digit industry classification. In the center panel, we only have two sectors: manufacturing and services. In the right panel, we have three sectors: manufacturing, low-skill services and high-skill services.

where $\Delta\left(x_{t}\right) \equiv\left(x_{t}-x_{s}\right) /(t-s)$ and $\overline{(x)} \equiv\left(x_{t}+x_{s}\right) / 2 .{ }^{11}$ The first term on the righthand side is the change in the occupational employment within each sector, weighted by the average employment share of the sector over the two years and then summed across all sectors. This term captures by how much occupational employment changed within sectors. The second term is the change in the employment share of each sector, multiplied by the average employment share of occupation $o$ in the sector over the two years and then summed over all sectors. This is the between-sector term that captures the change in occupational employment caused by changing employment at the sector level. A large between-sector term implies that technological change is at the sector level rather than the occupation level. On the other hand, a large within-sector term implies that the occupational employment changes are primarily driven by occupation-specific technological change.

Our data allows us to consistently use nine occupations in the 1-digit classification. For sectors, we consider three classifications. First, we use the 19 industries in the 1-digit industry classification. We then consider a simple manufacturing vs. service dichotomy, and finally divide services into high-skill and low-skill services to have three sectors. ${ }^{12}$ We compute the within-industry component for each occupation in a given country, and then average the within-component across the 9 occupations using occupational employment shares as weights.

\footnotetext{
${ }^{11}$ This decomposition follows Aum et al. (2017).

${ }^{12}$ Because STEP is a survey of urban areas only, we drop agriculture in our analysis.
} 
The results are shown in Figure 7. We first note that the within-sector component explains over 90 percent of occupational employment changes in the vast majority of countries, in all sector classifications, but especially with the 3-sector classification in the right panel. In other words, occupational employment has changed significantly within any given sector, implying that technological change at the occupation level is the dominant driver of overall occupational employment and hence task intensity changes in most countries. Second, the within-sector component is more important in richer countries. One interpretation is that technological change at the sector level and hence structural change play more important roles in developing countries than in developed ones, although they are still much less important than technological change at the task and occupation levels. This is consistent with the hypothesis in the literature that agriculture-to-manufacturing structural change may be offsetting de-routinization trends in developing countries (Das and Hilgenstock, 2018).

\section{Where to from Here}

To take stock, we re-visit the main question that motivates our paper. Are workers in developing countries and those in developed countries differentially exposed to technological change? As Sections 3 and 4 showed, the robust differences in task intensity across countries and its evolution over time suggest so. Our analysis showed that the initial occupational employment and the task contents of occupations in a country matter for the path of employment reallocation. This calls for caution when extrapolating what we know about the impact of technology on the labor market in developed countries to developing countries.

Whether this differential exposure implies disparities in the development path between developing countries and developed ones is still an open question, although the lack of evidence for convergence in Figure 5 suggests divergent paths. Another open question is whether the current occupational composition of the labor force influences a country's technology adoption decisions and the speed of labor reallocation in response to technological change-i.e., the economic mechanism behind Figure 6.

In order to more precisely illustrate our ideas, we now sketch a model of technology choice that endogenizes how task contents of an occupation vary across countries. The model can also be used for exploring how technological changes reallocate workers across jobs and affect the path of development. 


\subsection{A Simple Theoretical Framework and Open Questions}

An occupation (indexed by $o$ ) is a technology that produces output $y_{o}$ by combining tasks performed by workers. For expositional purposes, we here assume that occupational output is a CES aggregate of two tasks, analytical and manual, denoted by $a$ and $m$ :

$$
y_{o}=\left[\left(\tau_{a o} n_{a o}\right)^{\sigma_{o}}+\left(\tau_{m o} n_{m o}\right)^{\sigma_{o}}\right]^{1 / \sigma_{o}},
$$

where $1 /\left(1-\sigma_{o}\right)$ is the elasticity of substitution between the two tasks. Each task input is the product of the task units per efficiency unit of labor, $\tau$, and the efficiency units of labor assigned to the task, $n$. The efficiency units of labor are provided by the workers employed in the occupation, and a worker supplies both tasks. For example, the analytical task utilizes workers' math proficiency or IQ, while the manual task utilizes their physical strength or dexterity. In this example, the number of workers in an occupation (denoted by $q_{o}$ ) times their average math proficiency (denoted by $\bar{n}_{a o}$ ) is the total efficiency units assigned to the analytical task, $n_{a o} \equiv q_{o} \bar{n}_{a o}$. Similarly, the total efficiency units assigned to the manual task would be $n_{m o} \equiv q_{o} \bar{n}_{m o}$.

In the context of this occupation-level production technology, the task content or intensity measured by survey is $\tau_{a o} \bar{n}_{a o}$ and $\tau_{m o} \bar{n}_{m o}$. The average efficiency of workers, $\bar{n}_{a o}$ or $\bar{n}_{m o}$, is a part of the measured task content, because many survey questions in PIAAC and STEP ask the frequency of performing a given task, as shown in the Data Appendix. ${ }^{13}$

The observed disparities in task intensity across countries can be rationalized by endogenous choices of the task units per efficiency unit of labor, $\tau_{a o}$ and $\tau_{m o}$. For simplicity, we for now assume an exogenously given allocation of workers across occupations. ${ }^{14}$

The choice set of the technologies for an occupation in a country is the production possibility frontier (PPF) in the task space,

$$
\left(\tau_{a o}\right)^{\omega_{o}}+\gamma_{o}\left(\tau_{m o}\right)^{\omega_{o}} \leq B_{o}, \text { for } \gamma_{o}>0, \omega_{o}>1, B_{o}>0
$$

The parameter $B_{o}$ is the "height" of the PPF. The parameters $\omega_{o}$ and $\gamma_{o}$ determine its curvature and hence the tradeoff between tasks. This PPF is analogous to the one for skill-intensive technologies in Caselli and Coleman (2006).

\footnotetext{
${ }^{13}$ One could also compute task intensities by demographic groups, e.g., by gender and education attainment, which we view as a promising extension of our work.

${ }^{14}$ As we show below, this is a restrictive assumption: The average efficiency of workers $\bar{n}_{a o}$ and $\bar{n}_{m o}$ in an occupation determines the technology choice, and hence the selection of workers into occupations needs to be considered.
} 
The optimal choices of $\tau_{a o}$ and $\tau_{m o}$ satisfy, given the average efficiency of workers $\bar{n}_{a o}$ and $\bar{n}_{m o}$ :

$$
\frac{\tau_{a o} \bar{n}_{a o}}{\tau_{m o} \bar{n}_{m o}}=\gamma_{o}^{\frac{1}{\omega_{o}-\sigma_{o}}}\left(\frac{\bar{n}_{a o}}{\bar{n}_{m o}}\right)^{\frac{\omega_{o}}{\omega_{o}-\sigma_{o}}} \text { with } \omega_{o}-\sigma_{o}>0 .
$$

This condition highlights the determinants of a country's measured task contents $\left(\tau_{a o} \bar{n}_{a o}\right.$ and $\tau_{m o} \bar{n}_{m o}$ ) of an occupation. The first is the relative average efficiency of workers between tasks in the occupation, $\bar{n}_{a o} / \bar{n}_{m o}$, in a country. Countries with a higher average analytical efficiency of workers in the occupation relative to manual efficiency choose technologies that use analytical tasks more intensively. Second, this effect is stronger when the tasks are more substitutable in producing occupational output (a higher $\sigma_{o}$ ), as long as $\omega_{o}>\sigma_{o}$. When the tasks are complements in production $\left(\sigma_{o}<0\right)$, then the ratio of $\tau_{a o}$ to $\tau_{m o}$ is inversely related to $\bar{n}_{a o} / \bar{n}_{m o}$. Still, the measured relative task intensity on the left-hand side of equation (5) is positively related to $\bar{n}_{a o} / \bar{n}_{m o}$.

The natural next question is: What determines the relative average efficiency of workers between tasks in the occupation? The average task efficiency of workers $\bar{n}_{a o}$ and $\bar{n}_{m o}$ will be a function of their characteristics, such as schooling, experience, and other demographic variables. For example, college graduates and high-school graduates may supply the same amount of manual dexterity, but college graduates will supply more math and analytical proficiency than high-school graduates.

However, this does not necessarily mean that workers in countries with higher schooling attainment or better school quality perform relatively more analytical tasks in the occupation. What matters is the selection of workers with different characteristics into occupations, since the choice of occupation-level production function depends on the average efficiency of workers in each occupation. As a result, there will be non-trivial feedback between workers' occupational choices and the choice of occupation-level production technologies.

Indeed, the empirical evidence in Section 3 suggests that these selection effects are important. In developing countries, a higher fraction of workers are in occupations that are less intensive in NRA, NRI tasks and more intensive in RC, RM, NRM tasks. At the same time, workers in a given occupation perform relatively more NRA, NRI and relatively less RC, RM, NRM tasks than developed country workers in the same occupation. Worker selection can explain this pattern. As large fractions of workers in developed countries are in the NRA and NRI intensive occupations, the average analytical efficiency of these workers may be lower than the average of the select few workers working in these occupations in a developing country, consistent with the occupation-level NRA and NRI task intensity measured by the survey across countries. More broadly, it would be useful to make more progress on 
how differences in skill endowments shape technology choices, not only between occupations along the lines of Autor and Handel (2013), but also within an occupation.

Because the selection of workers into occupations affects the occupation-level technology choices, an important implication is that forces that shape the former, such as trade, offshoring, income effects that drive structural change, and broader technological changes also shape the latter. This points to the important effects that globalization, which may increase the demand for certain occupations relative to others even within a sector, can have on the technology choice and the development trajectory of developing countries.

Such changes in occupational employment are more pronounced among young cohorts of workers, who naturally move into occupations that expand, unbounded by occupationspecific human capital. Hobijn et al. (2018) document disparities in sectoral allocations of workers across cohorts in the US, and Adao et al. (2020) in Germany. Porzio et al. (2020) report similar patterns across countries in different stages of development. These differences could be caused by broader processes of de-industrialization, as emphasized by Rodrik (2016) and Huneeus and Rogerson (2020). We are unaware of such patterns across occupations, a dimension particularly informative about the direction of technological change, not only between occupations but also within occupations across tasks.

In addition, any distortions to the allocation of labor across occupations ultimately distort the choice of occupation-level production technology. For example, in Section 3.2 we documented systematic differences in the tasks performed by men and women across the development spectrum, which may be partly due to disparities in gender norms. Related, the problem of skill portability as workers move across occupations and sectors should be particularly relevant in understanding rural-urban migration incentives in the developing world. Investigations into the role of such market and non-market frictions affecting occupational choices should be a priority, which should be complemented by more work on the measurement of the mismatch between worker skill and task.

Such research that centers on worker heterogeneity will lead to another important open question that we are merely scratching the surface of: How the exposure to technological change is distributed across socio-economic groups within a country?

One possibility we have not considered up to now is that countries may have different "menus" of occupation-level production functions to choose from. Such a difference may result from disparate adoptions of modern technology, such as robots and artificial intelligence, that can fundamentally change the organization of production. For example, the 
occupation-level production function may be of the form:

$$
y_{o}=\left[\left(\left(A_{a o}\right)^{\eta_{a o}}+\left(\tau_{a o} n_{a o}\right)^{\eta_{a o}}\right)^{\frac{\sigma_{o}}{\eta_{a o}}}+\left(\left(A_{m o}\right)^{\eta_{m o}}+\left(\tau_{m o} n_{m o}\right)^{\eta_{m o}}\right)^{\frac{\sigma_{o}}{\eta_{m o}}}\right]^{1 / \sigma_{o}},
$$

where the use of artificial intelligence can be captured by the term $A_{a o}$ and the use of robots by $A_{m o}$, with $\eta_{a o}$ and $\eta_{m o}$ between 0 and 1 . In addition, various other factors, such as infrastructure, management practices, or market frictions and distortions, may show up as country-specific values of $\gamma_{o}$ and/or $B_{o}$, which can be one source of the cross-country difference in occupation-level technologies.

In the same context, perhaps the most important question is whether the occupation level technology choices can significantly amplify various frictions and distortions that generate mismatch between workers and tasks. Understanding the cross-country differences in occupational task contents and employment shares is the first step for answering this ultimate development question.

\subsection{Data Challenges and Needs}

To make progress in answering the questions highlighted in the previous section, we must overcome non-trivial data challenges. The first, and perhaps the biggest, challenge is the dearth of high-quality harmonized data that includes information on workers' demographic characteristics, occupations, and earnings. An important first step is the employment survey data collected by Donovan et al. (2020), available at https://www.Ifsdata.com/. Their data collection efforts emphasize the availability of rotating panels for the study of labor flows and expand the data currently available at ILO. Yet, earnings data is only available in half of their sample (21 countries), even though it is essential for answering questions about inequality. Another important step is the harmonization of household surveys, e.g. LSMS and labor force surveys from African countries, which includes ongoing work by Doss et al. (2020).

Similar limitations exist for consistent 3-digit occupational compositions of the labor force. IPUMS international data has detailed information on worker demographics and occupations (at the 1-digit level), but the time span is scattered across countries. For taskbased approaches, further disaggregation (i.e., at the 3-digit level) of occupations would be desirable.

Earnings or wage data is important for assessing the productivity of tasks performed by workers in different occupations as illustrated in the model above. Recent work by Hjort et al. (2020) document variation in the relative earning of middle managers across countries. 
Similarly, Saltiel (2020) explores earnings data in STEP to characterize task premia, for a limited set of countries. It is an open question whether the disparities in task intensity and occupational employment shown in Section 3 are consistent with disparities in relative earnings across occupations and countries.

Second, there is a need for detailed descriptions of occupational task contents and worker characteristics for countries at different levels of development, in a harmonized way. The PIAAC survey provides this information for middle- and high-income economies. The STEP survey focuses on poorer economies but, as we point out in Section 3, the wording of questions and the answer scales are different from those in PIAAC, making their comparison difficult. Further harmonization of these surveys would be a good first step. Additional effort to gather information in countries in Africa, Southwest Asia and the Middle East would be welcome. This includes collecting data on the task content of jobs in low-income countries, possibly as supplements to LSMS-ISA and labor force surveys. In particular, comparing the tasks performed by different groups of workers in a given occupation will allow for separating the technology ( $\tau$ in our model) from the worker skill $(\bar{n})$.

Finally, workers' tools, along with tasks, embody technological change. Unfortunately, information on the tools used by workers is not consistently available across countries. For the US, the O*NET lists tool requirements for each occupation. When merged with data on capital stock and prices, this can be used to measure workers' exposure to capital-embodied technological change (Caunedo et al., 2019). It is desirable to collect harmonized data across countries on tool requirements by occupation, as well as time series of capital stock and quality-adjusted prices of capital goods. The stock data includes ubiquitous equipments such as computers, but also broader equipment categories such as communication equipment, optical equipment, and robots. Currently available datasets on capital stock for a broad set of countries include PWT 9.1, which collects national accounts data in a harmonized way, and KLEMS data. The level of aggregation is perhaps too coarse to properly measure trends in capital-embodied technological change across occupations-e.g., structures, machinery, transport, and other. The data on tasks and tool requirements of occupations could be collected as a module in LSMS-ISA and labor force surveys. In terms of prices, the latest publicly available ICP benchmark data dates from more than 20 years ago, 1996. Efforts to make these detailed price data available to researchers would greatly improve our ability to answer the promising research questions above. Methodological contributions to the inference of technological change from limited cross-country data would also be another venue for progress. 


\section{$6 \quad$ Policy Implications and Concluding Remarks}

We believe that answering the questions posed throughout this paper would greatly advance our understanding of the role of policy interventions in boosting growth while cognizant of their distributional effects. Recently, technological change and rising inequality have been emphasized as two linked phenomena, particularly within developed economies. But throughout history this was not always the case. The post-World War period was one characterized by strong growth, technological advances, and improvements in income levels across the board that shrank income inequality.

Policymakers can start with removing barriers and distortions that deter the reallocation of workers driven by technological change, which will make the economy more efficient. It is also important to further study the link between frictions in the labor market and incentives to adopt new technology.

Equally important is the study of the policies that can foster human capital accumulation through schooling, job training, and re-training so that workers can fully utilize and benefit from the ongoing technological progress.

Not everyone will benefit from technological change and some will fall through the cracks. Practitioners and academics alike will need to renew our thinking on the optimal design of social safety nets. Incorporating job informality, a pervasive problem in poorer economies, should be a priority. 


\section{References}

Acemoglu, D. and D. Autor (2011). Skills, tasks and technologies: Implications for employment and earnings. In O. Ashenfelter and D. Card (Eds.), Handbook of Labor Economics (1 ed.), Volume 4B, Chapter 12, pp. 1043-1171. Elsevier.

Acemoglu, D. and P. Restrepo (2019, Spring). Automation and new tasks: How technology displaces and reinstates labor. Journal of Economic Perspectives 33(2), 3-30.

Adao, R., M. Beraja, and N. Pandalai-Nayar (2020, January). Technological transitions with skill heterogeneity across generations. NBER Working Papers 26625, National Bureau of Economic Research, Inc.

Aghion, P., C. Antonin, S. Bunel, and X. Jaravel (2020, February). What are the labor and product market effects of automation? new evidence from france. CEPR Discussion Papers 14443, C.E.P.R. Discussion Papers.

Aghion, P., B. F. Jones, and C. I. Jones (2018). Artificial intelligence and economic growth. In The Economics of Artificial Intelligence: An Agenda, NBER Chapters, pp. 237-282. National Bureau of Economic Research, Inc.

Akerman, A., I. Gaarder, and M. Mogstad (2015). The skill complementarity of broadband internet. The Quarterly Journal of Economics 130(4), 1781-1824.

Almeida, R. K., A. M. Fernandes, and M. Viollaz (2017). Does the adoption of complex software impact employment composition and the skill content of occupations? evidence from chilean firms. Working Paper 8110, The World Bank.

Aum, S. (2017). The rise of software and skill demand reversal. Unpublished manuscript.

Aum, S., S. Y. T. Lee, and Y. Shin (2017). Industrial and occupational employment changes during the Great Recession. Federal Reserve Bank of St. Louis Review 99(4), 307-317.

Aum, S., S. Y. T. Lee, and Y. Shin (2018). Computerizing industries and routinizing jobs: Explaining trends in aggregate productivity. Journal of Monetary Economics 97, 1-21.

Autor, D. and M. Handel (2013). Putting tasks to the test: Human capital, job tasks, and wages. Journal of Labor Economics 31 (S1), S59 - S96.

Autor, D. H. and D. Dorn (2013, August). The growth of low-skill service jobs and the polarization of the US labor market. American Economic Review 103(5), 1553-97. 
Autor, D. H., L. F. Katz, and M. S. Kearney (2006, May). The polarization of the u.s. labor market. American Economic Review 96(2), 189-194.

Autor, D. H., F. Levy, and R. J. Murnane (2003). The skill content of recent technological change: An empirical exploration. The Quarterly Journal of Economics 118(4), 12791333.

Barany, Z. L. and C. Siegel (2018, January). Job polarization and structural change. American Economic Journal: Macroeconomics 10(1), 57-89.

Beaudry, P., D. Green, and B. Sand (2016). The great reversal in the demand for skill and cognitive tasks. Journal of Labor Economics 34 (S1), S199 - S247.

Caselli, F. and I. Coleman, Wilbur John (2006, June). The world technology frontier. American Economic Review 96(3), 499-522.

Caunedo, J., D. Jaume, and E. Keller (2019). Occupational exposure to capital-embodied technology. Unpublished manuscript.

Das, M. and B. Hilgenstock (2018). The exposure to routinization: Labor market implications for developed and developing economies. Working Paper 18/135, IMF.

Donovan, K., W. J. Lu, and T. Schoellman (2020). Labor market dynamics and development. Unpublished manuscript.

Doss, C., D. Gollin, C. Gottlieb, M. Poschke, R. Santaeulalia-Llopis, and B. Zhang (2020). Gender, work and structural transformation. Unpublished manuscript.

Duernecker, G. and B. Herrendorf (2016, February). Structural transformation of occupation employment. Unpublished manuscript.

Fernández, R., A. Fogli, and C. Olivetti (2004). Mothers and sons: Preference formation and female labor force dynamics. The Quarterly Journal of Economics 119(4), 1249-1299.

Galor, O. and D. N. Weil (1996, June). The gender gap, fertility, and growth. American Economic Review 86(3), 374-87.

Goldin, C. (2014, April). A grand gender convergence: Its last chapter. American Economic Review 104(4), 1091-1119. 
Goldin, C. and L. F. Katz (2012, September). The most egalitarian of all professions: Pharmacy and the evolution of a family-friendly occupation. NBER Working Papers 18410, National Bureau of Economic Research, Inc.

Goos, M., A. Manning, and A. Salomons (2014). Explaining job polarization: Routine-biased technological change and offshoring. American Economic Review 104(8), 2509-26.

Gottlieb, C., J. Grobovsek, M. Poschke, and F. Saltiel (2020). Working from home in developing countries. Unpublished manuscript.

Hallward-Driemeier, M. C. and G. Nayyar (2017). Trouble in the Making?: The Future of Manufacturing-led Development. Washington, D.C.: World Bank Group.

Handel, M. J. (2012). Trends in job skill demands in OECD countries. Working Paper 143, OECD.

Hicks, J. (1932). The Theory of Wages. MacMillan.

Hjort, J., H. Malmberg, and T. Schoellman (2020). The missing middle managers: Labor costs, firm structure, and development. Unpublished manuscript.

Hjort, J. and J. Poulsen (2019, March). The arrival of fast internet and employment in africa. American Economic Review 109(3), 1032-1079.

Hobijn, B., T. Schoellman, and A. Vindas (2018). Structural transformation by cohort. Unpublished manuscript, Arizona State University.

Hsieh, C.-T., E. Hurst, C. I. Jones, and P. J. Klenow (2019, September). The allocation of talent and u.s. economic growth. Econometrica 87(5), 1439-1474.

Hsieh, C.-T. and P. J. Klenow (2007, June). Relative prices and relative prosperity. American Economic Review 97(3), 562-585.

Huneeus, F. and R. Rogerson (2020, July). Heterogeneous paths of industrialization. Unpublished manuscript.

Katz, L. F. and K. M. Murphy (1992). Changes in relative wages, 1963-1987: Supply and demand factors. The Quarterly Journal of Economics 107(1), 35-78.

Lee, D. and K. I. Wolpin (2006, January). Intersectoral labor mobility and the growth of the service sector. Econometrica $74(1), 1-46$. 
Lee, S. Y. T. and Y. Shin (2017). Horizontal and vertical polarization: Task-specific technological change in a multi-sector economy. Working Paper 23283, NBER.

Lewandowski, P., A. Park, W. Hardy, and D. Yang (2019, April). Technology, skills, and globalization: Explaining international differences in routine and nonroutine work using survey data. Working Paper 2019-60, HKUST Institute for Emerging Market Studies.

Lewandowski, P., A. Park, and S. Schotte (2020, June). The global distribution of routine and non-routine work. Discussion Paper 13384, Institute of Labor Economics (IZA).

Lo Bello, S., M. L. Sanchez Puerta, and H. J. Winkler (2019, February). From Ghana to America : The skill content of jobs and economic development. Working Paper 8758, The World Bank.

Maloney, W. F. and C. A. Molina (2016, December). Are automation and trade polarizing developing country labor markets, too? Policy Research Working Paper Series 7922, The World Bank.

Ngai, L. R. and B. Petrongolo (2017). Gender gaps and the rise of the service economy. American Economic Journal: Macroeconomics 9(4), 1-44.

Porzio, T., F. Rossi, and G. Santangelo (2020). The human side of structural transformation. Unpublished manuscript.

Rendall, M. P. (2010, September). Brain versus brawn: The realization of women's comparative advantage. Working Paper 491, Institute for Empirical Research in Economics.

Robinson, J. (1934). The economics of imperfect competition. Journal of the Royal Statistical Society 97(4), 671-674.

Rodrik, D. (2016). Premature deindustrialization. Journal of Economic Growth 21(1), 1-33.

Saltiel, F. (2020). Comparative evidence on the returns to tasks in developing countries. Unpublished manuscript.

Vizcaino, J. I. (2019). Skills, technologies and development. Unpublished manuscript. 


\section{A Additional Tables and Figures}

Regression of task intensity, O*NET versus our own measures:

$$
N R A_{c k}=\beta_{0}+\beta_{1} \log (G D P P C)_{c}+\beta_{2} T y p e_{k}+\beta_{3} \log (G D P P C)_{c} \times T y p e_{k}+\epsilon_{c k}
$$

where Type $_{k}=1$ denotes measures from country specific task content, while Type $e_{k}=0$ denotes measures from $\mathrm{O}^{*} \mathrm{NET}$.

Table 6: Decomposition Using O*NET as Benchmark

\begin{tabular}{lccccc}
\hline & NRA & NRI & RC & RM & NRM \\
\hline $\log ($ GDP Per Capita) & $0.0765^{* * *}$ & $0.112^{* * *}$ & $0.0899^{* * *}$ & $-0.307^{* * *}$ & $-0.287^{* * *}$ \\
& $(0.0283)$ & $(0.0244)$ & $(0.0213)$ & $(0.0156)$ & $(0.0166)$ \\
$\log \left(\right.$ GDP Per Capita) $\times$ Type $_{k}$ & -0.0261 & $-0.0758^{* *}$ & $-0.115^{* * *}$ & $0.273^{* * *}$ & $0.277^{* * *}$ \\
& $(0.0400)$ & $(0.0345)$ & $(0.0301)$ & $(0.0220)$ & $(0.0234)$ \\
Type $_{k}$ & 0.249 & $0.864^{* *}$ & $1.284^{* * *}$ & $-3.024^{* * *}$ & $-3.104^{* * *}$ \\
& $(0.410)$ & $(0.354)$ & $(0.309)$ & $(0.226)$ & $(0.240)$ \\
Intercept & $-0.808^{* * *}$ & $-1.287^{* * *}$ & $-1.005^{* * *}$ & $3.397^{* * *}$ & $3.206^{* * *}$ \\
\hline$N$ & $(0.290)$ & $(0.250)$ & $(0.218)$ & $(0.160)$ & $(0.170)$ \\
$R^{2}$ & 84 & 84 & 84 & 84 & 84 \\
\hline
\end{tabular}

Note: This table shows regression results to test whether the task content measures from O*NET and those following our assignment have significantly different slopes against GDP per capita. Type ${ }_{k}=1$ denotes measures from country specific task content, while Type $_{k}=0$ denotes measures from O*NET. 
Figure 8: Task Intensity Change and Task Intensity in 2006, US-based Task Measure

(a) NRA

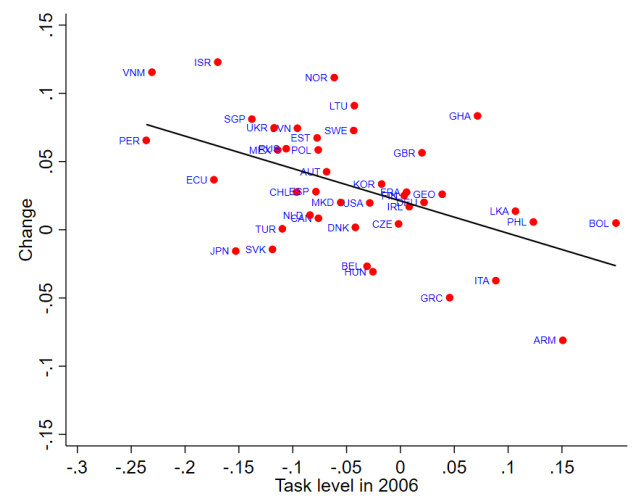

(c) RC

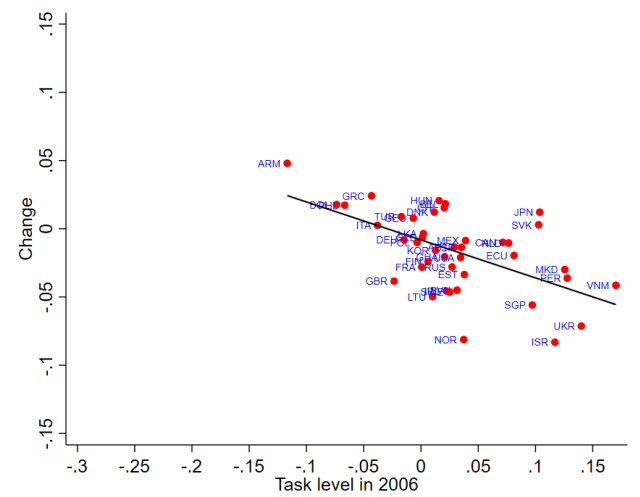

(b) NRI

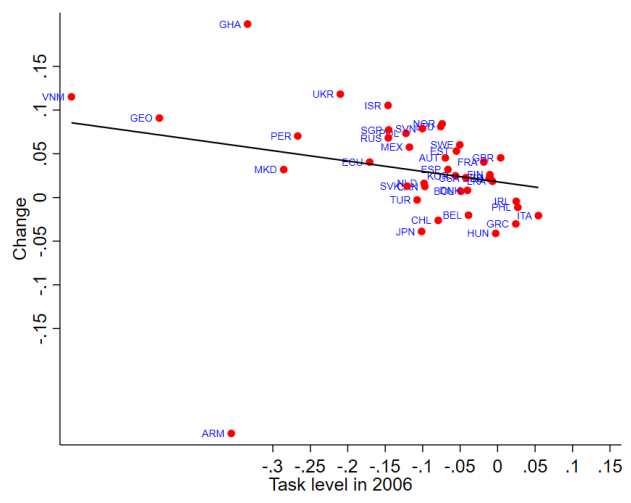

(d) RM

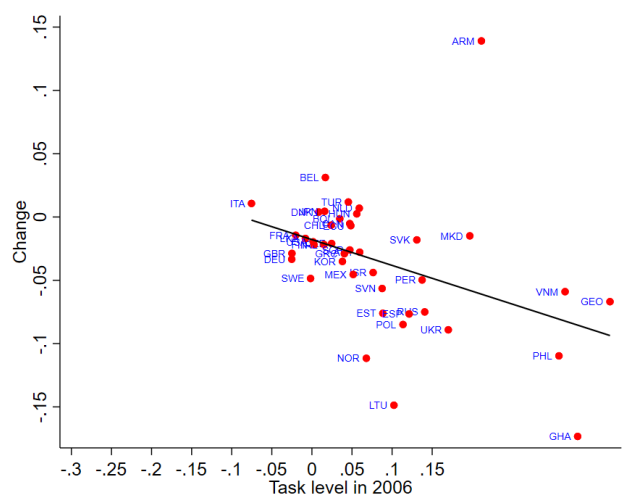

(e) NRM

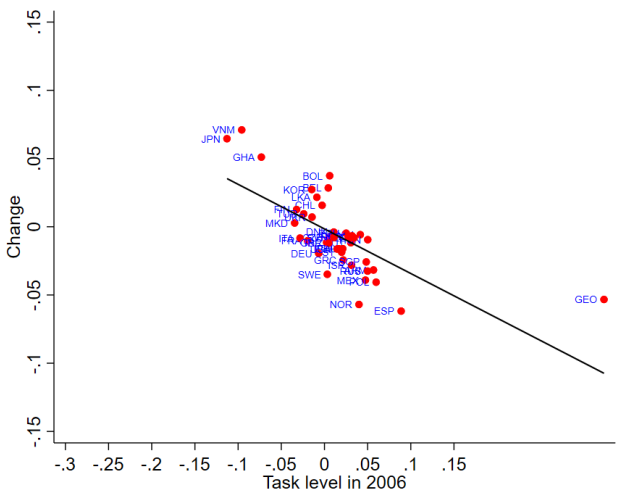

Note: This figure shows the change in task intensity between 2006 and 2015 against the task intensity in 2006 for each country. The change in task intensity is solely accounted for by the occupational employment changes between 2006 and 2015, where occupational task content is based on the US O*NET and assumed the same for all countries. 